\title{
Komani (Dalmace), Albanie. Bilan de la mission franco-albanaise des campagnes 2018-2019
}

Etleva Nallbani, Yann Bonfand, Jocelyne Desideri et Elvana Metalla

\section{(2) OpenEdition}

Journals

Édition électronique

URL : http://journals.openedition.org/cefr/4264

DOI : $10.4000 /$ cefr.4264

ISSN : 2282-5703

Éditeur

École française de Rome

Référence électronique

Etleva Nallbani, Yann Bonfand, Jocelyne Desideri et Elvana Metalla, « Komani (Dalmace), Albanie. Bilan de la mission franco-albanaise des campagnes 2018-2019 », Chronique des activités archéologiques de l'École française de Rome [En ligne], Balkans, mis en ligne le 27 avril 2020, consulté le 27 avril 2020. URL : http://journals.openedition.org/cefr/4264; DOI : https://doi.org/10.4000/cefr.4264

Ce document a été généré automatiquement le 27 avril 2020

(C) École française de Rome 


\title{
Komani (Dalmace), Albanie. Bilan de la mission franco-albanaise des campagnes 2018-2019
}

\author{
Etleva Nallbani, Yann Bonfand, Jocelyne Desideri et Elvana Metalla
}

\section{NOTE DE L'AUTEUR}

Le projet de collaboration franco-albanais sur le site de Komani poursuit le partenariat entre l'EFR, l'UMR 8167 « Orient et Méditerranée » (CNRS) et l'Institut d'archéologie de Tirana, sous la forme de la mission archéologique « La basse vallée du Drin ». Un partenariat annexe a été établi en 2017 entre l'Université de Genève et l'EFR. Le financement des recherches est assuré par le ministère de l'Europe et des Affaires étrangères et européennes français, l'EFR, le CNRS (UMR 8167 « Orient et Méditerranée » et UMR 7264 CEPAM), le Labex RESMED, la Société académique de Genève et les institutions albanaises de la recherche et du patrimoine via l'Institut d'archéologie de Tirana et le Directorat régional du patrimoine culturel de Shkodra (DRTK). Nous leur exprimons toute notre gratitude.

Les missions de terrain 2018-2019 ont réuni, en plus des auteurs de ce texte, V. Gallien, I. Richard (CNRS, UMR 7264 CEPAM et INRAP), W. Boutenbat (Sorbonne Université), M. Ferrari (INRAP), L. et M. Buchet (CNRS, UMR 7274 CEPAM), P. Baillet (CNRS, UMR 7274 CEPAM), J. Debard, D. Rosselet, G. Kottas, A. Bridy (Université de Genève), S. Vatteoni (Communauté d'agglomération de Douaisis - Direction de l'archéologie préventive), H. Sokoli et D. Margjoni (respectivement archéologue et restaurateur du Directorat régional du Patrimoine culturel/DRTK de Shkodra), E. Bitri (restaurateur d'Art restauration conservation studio-ARCS), O. Durmishaj (Parc archéologique d'Apollonia), U. Tota (université d'Avignon et Institut d'archéologie de Tirana), K. Çipa (DRTK de Vlora), A. Matarese (Université de Bourgogne), E. Courné (Université Paris 1) et P. Mollard (Sorbonne Université) ; B. Grümil, restauratrice (Haute École de conservation et restauration de biens culturels de Galice, l'ESCRBCG), U. Comesaña, 
A. Comesaña, D. Noya et A. Municio (étudiants à l'ESCRBCG), J. Llanaj, A. Qazimi, P. Hoxha et A. Myftari (Université de Tirana), M. Pétronille (Tellus Environnement), R. Mihali (COSPE), à qui nous adressons tous nos remerciements. Nos remerciements vont également aux habitants de Komani, de Shën Koll et des villages alentour, en particulier à M. et K. Doçaj, Z. Hajdaraj, R. Nikaj et sa famille, pour l'organisation de la logistique et la facilité avec laquelle ils ont mis à la disposition de l'équipe leurs complexes hôtelier, restaurant, leurs terrains et leurs services.

1 Trois missions de terrain ont été menées à Komani et à Sarda, dont une télédétection au Lidar (du 5-9 décembre 2018) et deux opérations de fouilles, de consolidations et de restauration, accompagnées d'étude du mobilier (du 24 juillet au 30 août 2018 et du $1^{\text {er }}$ juillet au 27 août 2019). Ces deux opérations consistantes de terrain ont réuni, en 2018, une équipe de vingt-six spécialistes et étudiants et d'une vingtaine d'ouvriers; en 2019, vingt-huit spécialistes et étudiants et quinze ouvriers. L'étude du mobilier anthropologique et archéologique a réuni cinq spécialistes en 2018 et neuf en 2019, alternant leur séjour entre la "Villa française " située en bas dans le village et les hauteurs de site de Dalmace. La campagne de terrain de 2019 a profité de la pratique de consolidation et restauration, réalisée dans le cadre d'un Erasmus avec la Haute École de conservation et restauration de biens culturels de Galice.

\section{Mission de télédétection au Lidar}

Une télédétection au Lidar a été réalisée en décembre 2018, sur Sarda et à Komani. Pour ce dernier site, l'opération a rencontré des difficultés techniques dues à sa vaste superficie et à la nature accidentée du terrain. Les résultats préliminaires de cette prospection par imagerie permettent déjà une lecture des structures de Sarda (4 ha), destinée à mieux cibler les interventions futures sur le terrain, tant en termes de fouille que de protection des vestiges (fig. 1). Quant au territoire de Komani, le résultat concerne uniquement sa périphérie (environ $80 \mathrm{ha}$ ), où des modifications du paysage, liées à une forte activité humaine depuis des siècles (exploitation minière, déforestation etc.) et aux conditions naturelles (fortes érosions), ont été mises en évidence (fig. 2). Ce résultat offre de nouvelles pistes de recherches, tournées vers l'archéologie de l'environnement et une meilleure compréhension de l'activité humaine dans son environnement. 
Fig. 1 - Sarda. Image de l'île par la télédétection au Lidar.

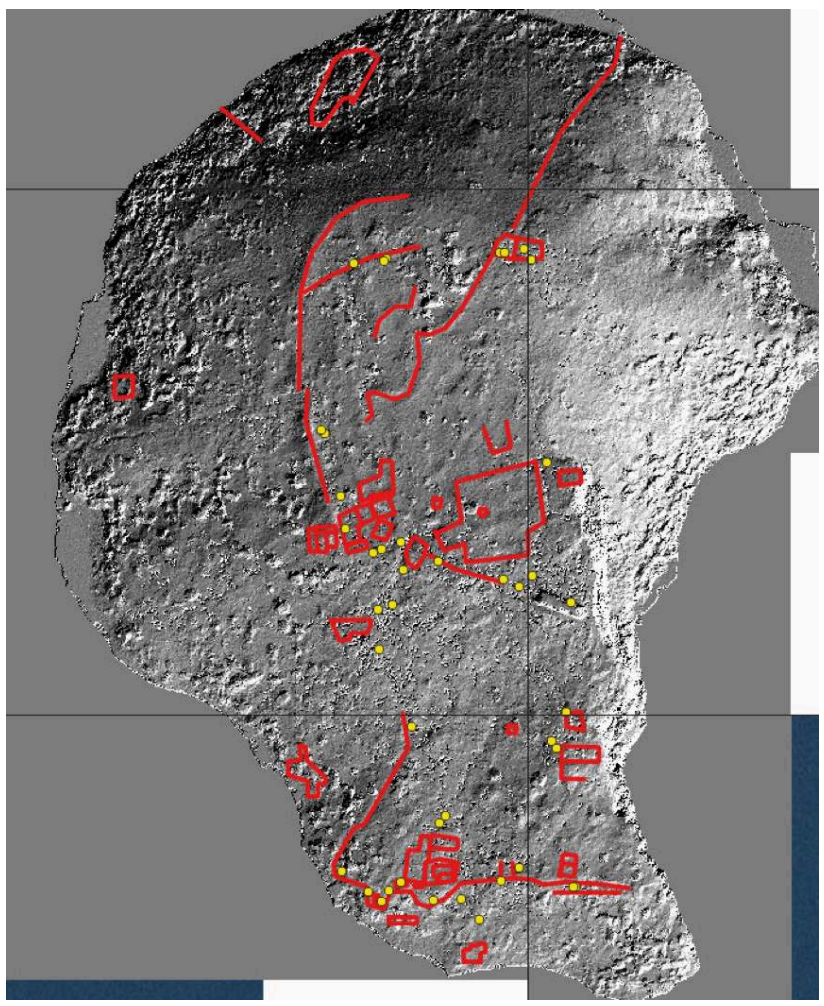

(c) Mission archéologique «Basse vallée du Drin », Cl. Tellus Environement.

Fig. 2 - Komani. Image du versant nord des hauteurs du site.

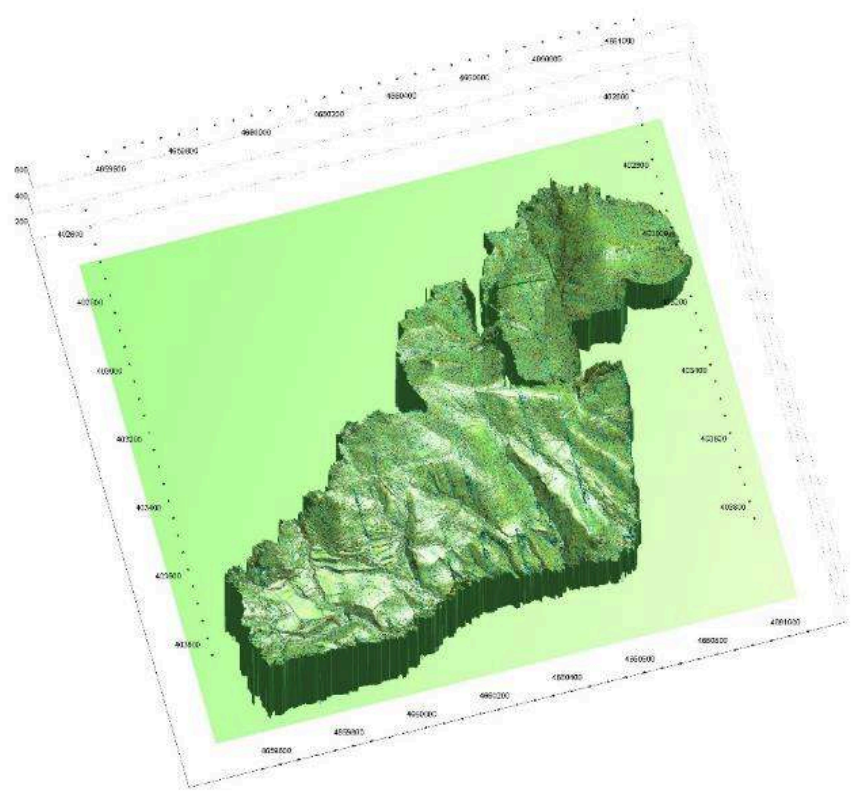

(c) Mission archéologique «Basse vallée du Drin », Cl. Tellus Environement. 


\section{Opérations de fouille}

3 Les opérations de fouille à Komani ont permis d'approfondir les investigations sur deux secteurs majeurs du site, dont celui du complexe ecclésial, « zone 1B », de la colline dite « de la citadelle » et sur le secteur de la nécropole principale (zones 2 et 3), dans la suite des opérations des campagnes précédentes.

\section{Zone 1B, l'église}

4 L'église installée dans la partie sommitale de la zone $1 \mathrm{~B}$, très près de la falaise, se révèle étant le monument le plus important du site, dans l'état actuel de notre connaissance (engagée 2012, 2014-2017) et sa découverte a pris toute notre attention.

\section{État des connaissances}

5 À l'issue des opérations de terrain de 2017, nous connaissions un état final de l'église médiévale, composée pour l'essentiel d'un collatéral nord et d'une nef munie de nombreuses et très riches installations liturgiques ${ }^{1}$ : le cœur avec synthronon et cathèdre, vasque et installations liturgiques de part et d'autre de l'apside, pied de table d'autel, et de nombreuses banquettes (fig. 3).

Fig. 3 -Zone 1B. Plan de l'église après la campagne 2017.

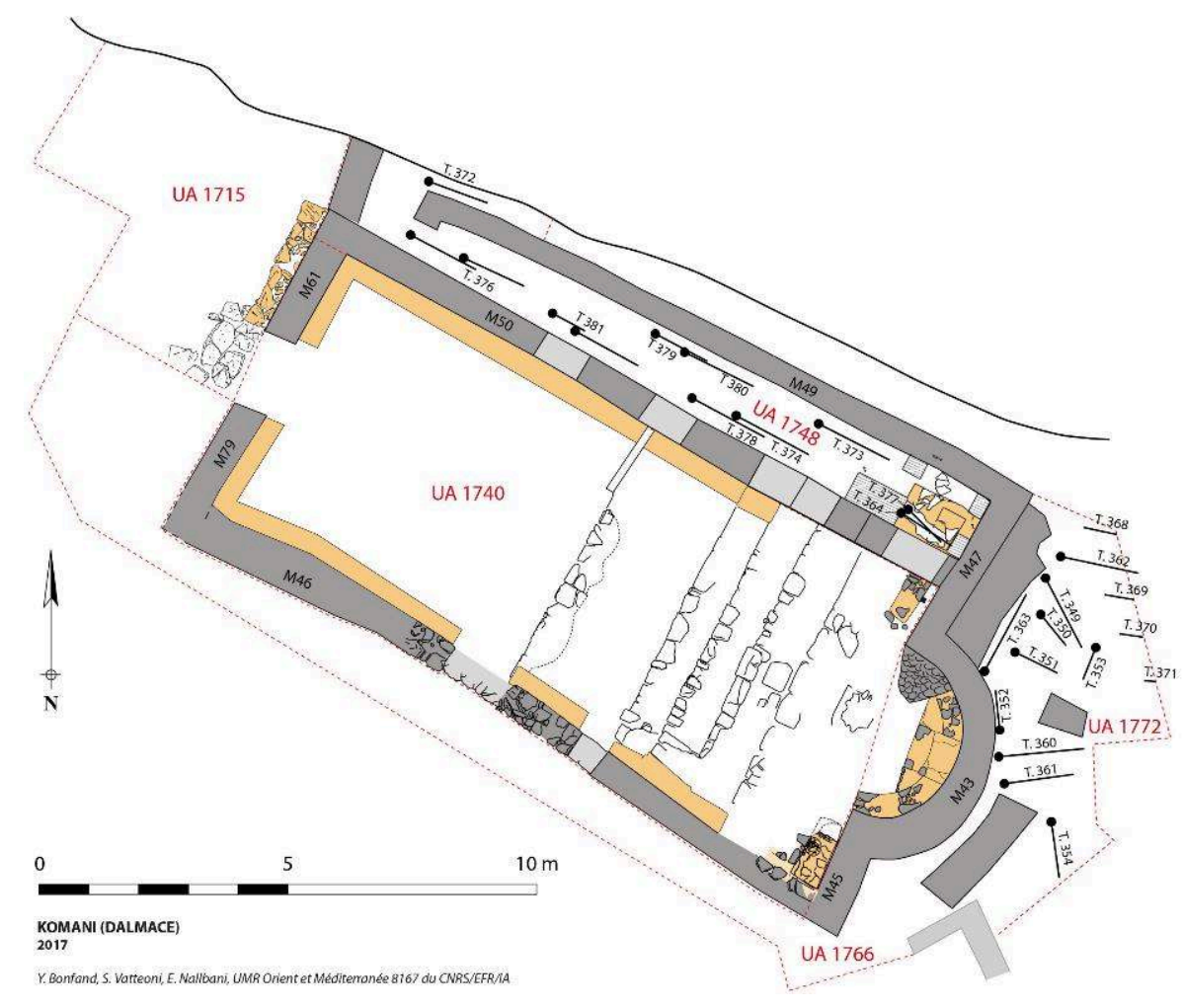

(c) Mission archéologique «Basse vallée du Drin », DAO : Y. Bonfand, S. Vatteoni, E. Nallbani.

Les installations liturgiques semblaient clairement appartenir à un état tardif de l'église, par ailleurs toutes couvertes d'une couche d'enduit beige étalée également sur les bancs et les sols et d'enduit peint sur les murs, superposé par endroit, au moins à 
deux autres couches plus anciennes. Le panneau d'enduit peint, du mur nord de la nef, effondré, qui porte une formule de prière ${ }^{2}$, pourrait dater entre le $\mathrm{XI}^{\mathrm{e}}$ et le $\mathrm{XII}^{\mathrm{e}}$ siècle. De cette phase médiévale doivent aussi appartenir les sépultures installées au chevet, dont les niveaux les plus tardifs remontent (par analyses au C14) à la seconde moitié du $\mathrm{XII}^{\mathrm{e}}$ au XIII ${ }^{\mathrm{e}}$ siècle. Onze tombes ont été installées dans le collatéral, tranchant l'ancien niveau de sol, dont les datations précises restent à déterminer.

Or l'église a livré des fragments de peinture plus ancienne, hormis le panneau avec la figure de l'animal (fig. 4), ainsi que des fragments de lampes en verre ${ }^{3}$, d'un enfouissement volontaire (rituel ?) à l'intérieur du lavabo liturgique, dans la zone du presbytère et dans l'annexe nord, ce dernier emplacement lié probablement à une table d'autel latérale.

Fig. 4 - Scène figurée peinte sur enduit.

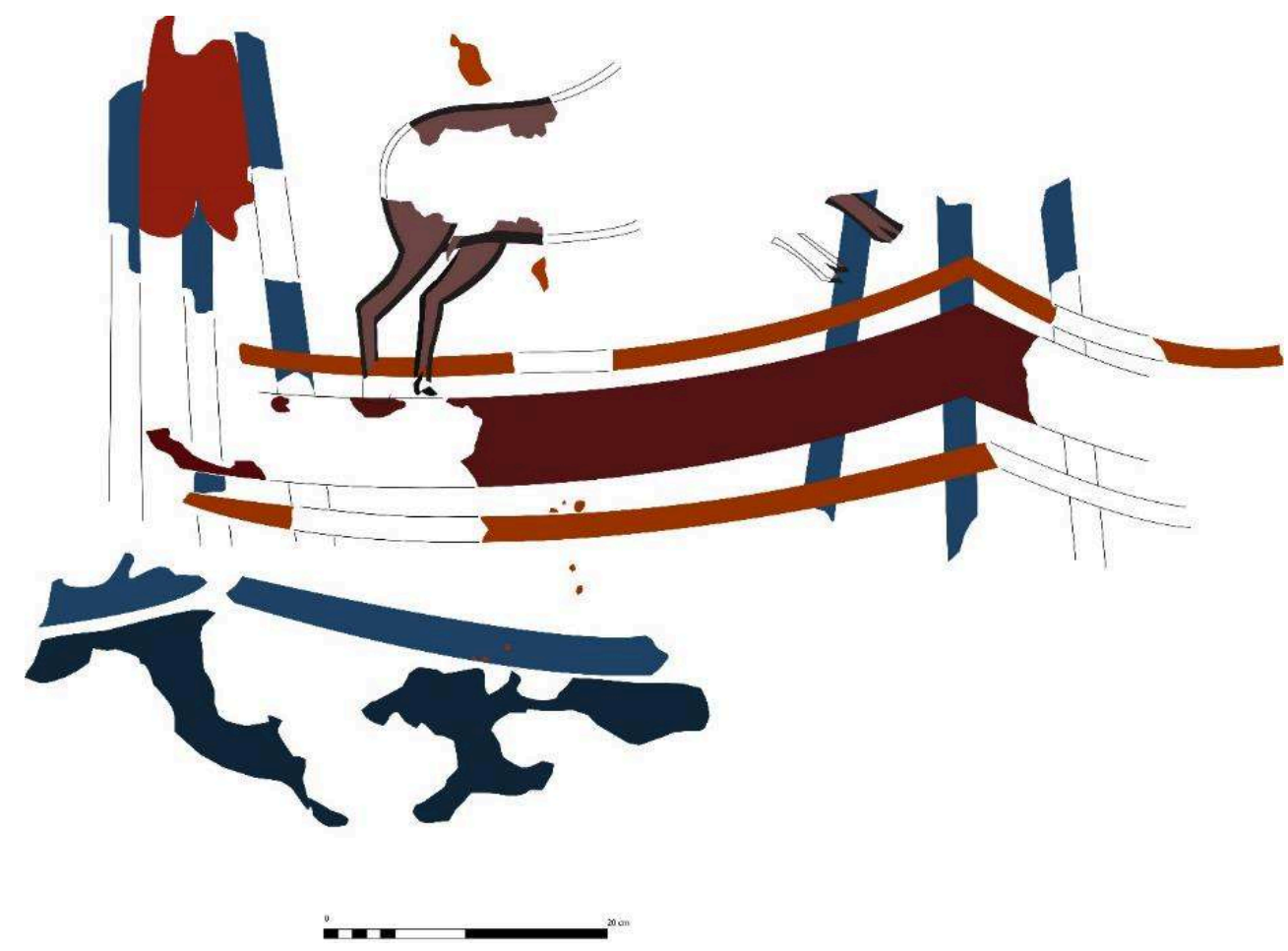

(c) Mission archéologique «Basse vallée du Drin », DAO : Y. Bonfand.

8 Les deux sondages 1933 et 1952, engagés en 2017, dans le système des marches vers le cœur et à l'intérieur de l'entré sud de l'église, ont définitivement validé l'hypothèse d'états antérieurs à ceux que nous appréhendons. Le sondage 1933 (fig. 5) ouvert sur toute la largeur de la marche 1837 (1,50 m), a annoncé l'existence d'un autre système de marches, sur lequel serait déposé celui de la phase médiévale ; le sondage 1952, effectué dans la partie sud-ouest de la nef, avant la première marche qui scinde l'église en deux et au droit de l'accès sud, a présenté une succession d'au moins 6 sols de facture différente, attestant ainsi de profonds changements dans l'église, de la volonté de réfection régulières et surtout d'une utilisation longue du bâtiment. 
Fig. 5 - Zone 1B. Église. Sondage 1933 réalisé en 2017.

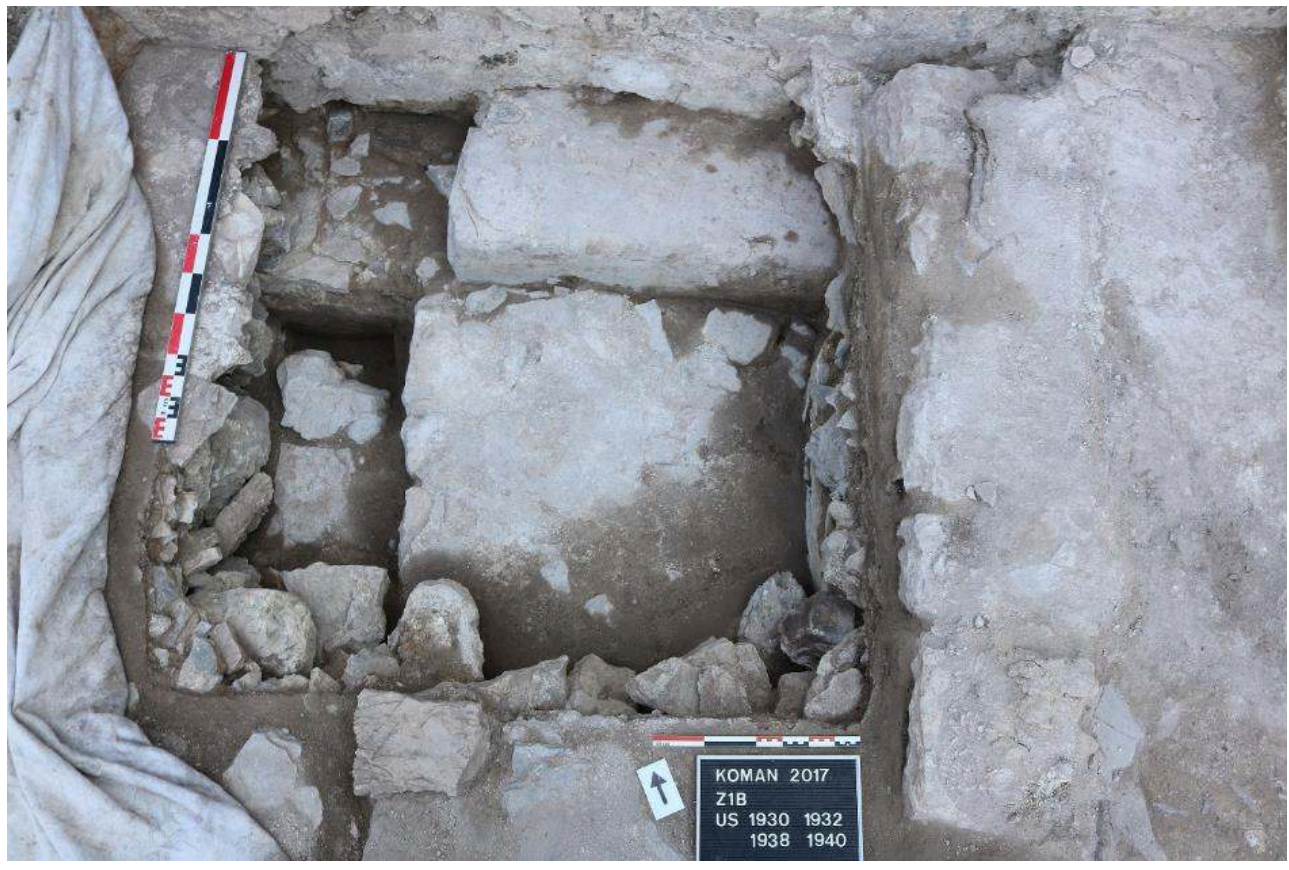

Cl. Y. Bonfand.

\section{Étude du mobilier archéologique de l'église}

9 Une mission d'étude s'est déroulée en 2018, qui a consisté à la documentation et aux premières restitutions des fragments d'enduits, peints ou non, des blocs d'architecture en tuf et les décors moulés en stuc. Le grand nombre d'environ 247 blocs en tuf taillés révèle des impostes, des bases et des fragments de colonnes, des claveaux, tous provenant des niveaux de destruction immédiatement supérieurs dans le chœur de l'église. Une première concentration, les US 1739, 1749 et 1759 - essentiellement au centre de la nef, à la hauteur de la première marche au droit de la porte sud doit attester la présence d'une chancelle majoritairement en tuf (fig. 6). L'autre concentration, dans les US 1918, 1929 et 1942, devant le chevet et à proximité immédiate de l'autel (fig. 7), doit correspondre à d'autres infrastructures en tuf, comme par ailleurs les composants des deux dispositifs liturgiques de part et d'autre de l'abside (fig. 8). 
Fig. 6 - Zone 1B. Église. Structure 1839, chancel ? Vue nord-sud.

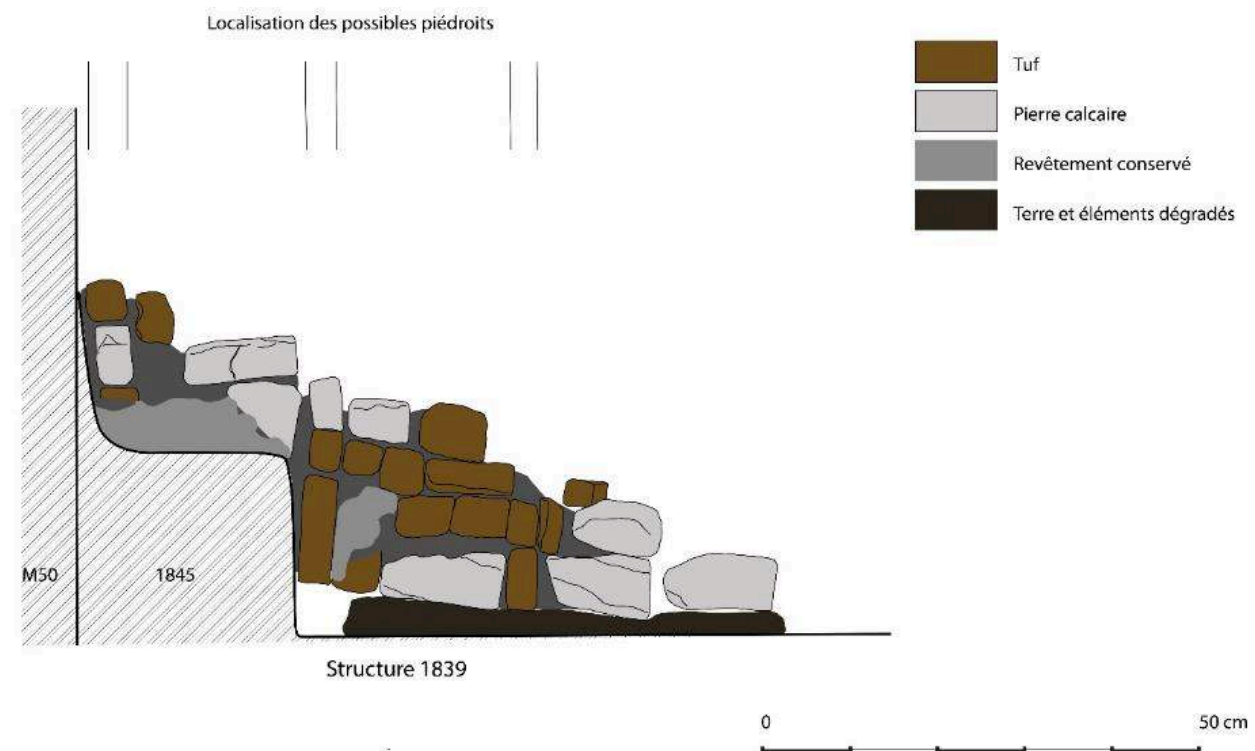

DAO: Y. Bonfand

DAO : Y. Bonfand

Fig. 7 - Blocs de tuf éboulés contre le pied de l'autel.

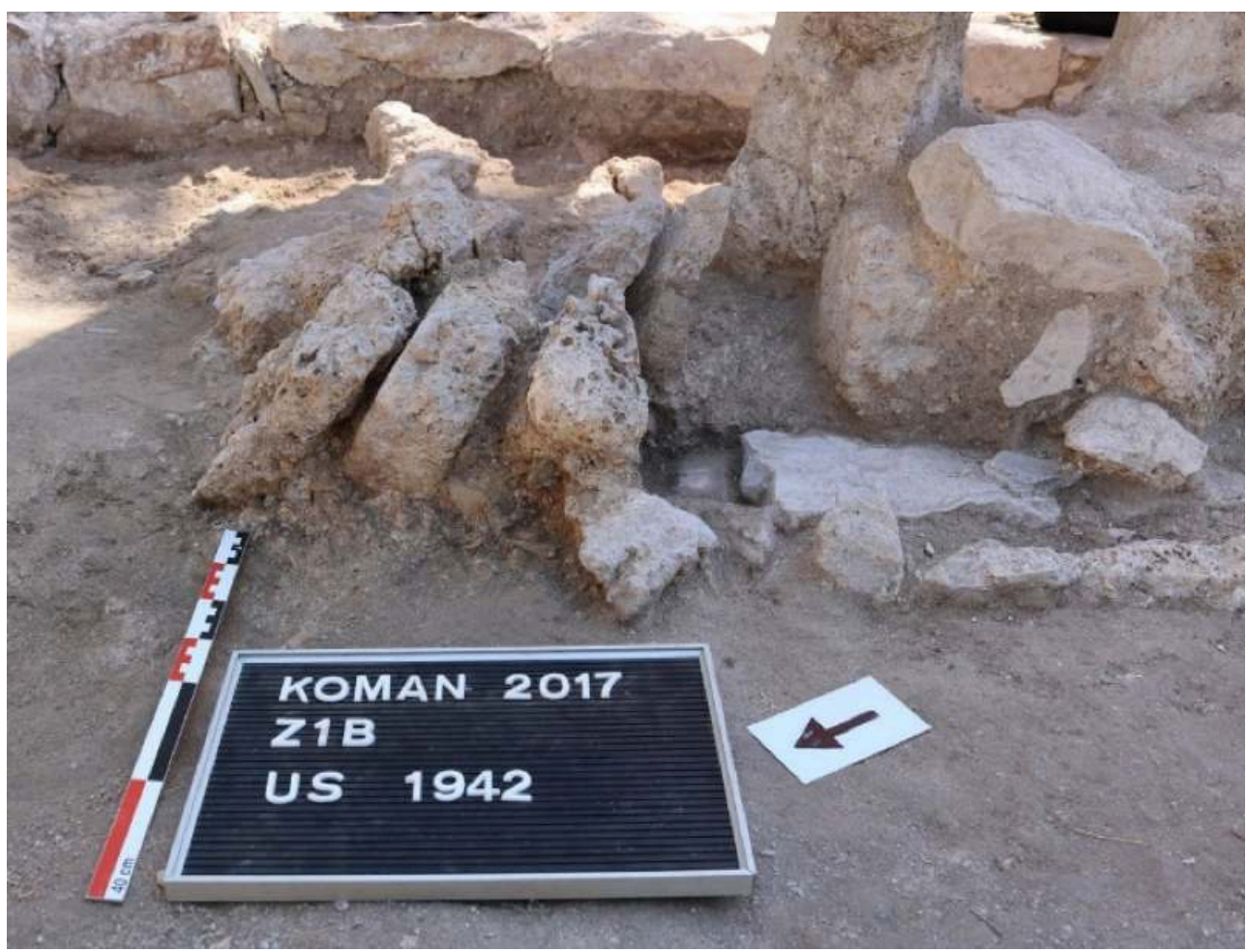

Cl. Y. Bonfand. 
Fig. 8 - Église, zone 1B. Aménagement liturgique sud, dit « lavabo ».
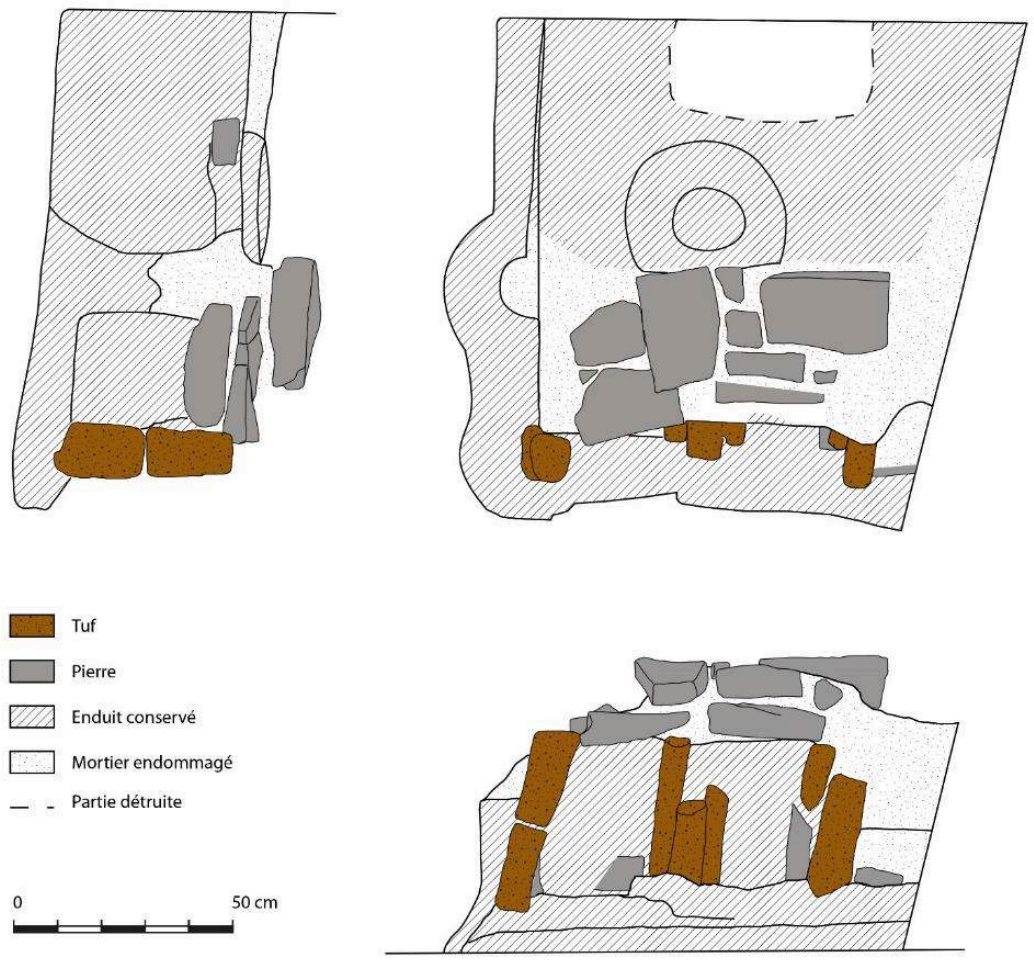

Relevé:W. Boutenbat; DAO:Y. Bonfand

Relevé : W. Boutenbat; DAO : Y. Bonfand.

10 L'étude a porté sur de nombreux fragments de plâtre enduite, de taille et forme très variable, dont la majorité concentrée autour de l'autel, spécialement sur la marche 1838. Trois types essentiels de vestiges décoratifs en "stuc» ont pu être observés : les points de diamants (exclusivement dans l'US 1904), au niveau de l'abside de l'église dont la grande variété de tailles et formes indique que ces éléments façonnés individuellement étaient appliqués contre un support (fig. 9). Deux grands ensembles sont à différencier et pourraient renvoyer à deux espaces différents d'implantation. Ces " pointes de diamant » devaient nécessairement surmonter le synthronon et seraient appliquées logiquement sur une voûte en cul-de-four.

Fig. 9 - Zone 1B. Église. Pointes de diamants (US 1904 et 1918).

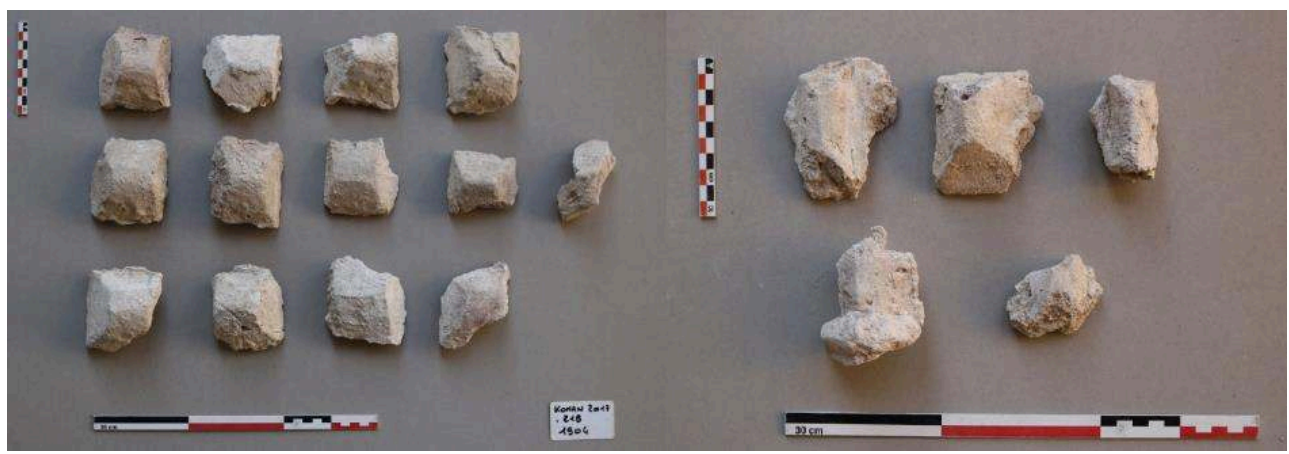

Cl. W. Boutenbat.

Les niveaux de destruction du chœur ont livré un très grand nombre de petits éléments d'enduits, plâtres et mortiers, comme bords d'encadrements et tables, angles ou 
bordure de cloison, bord circulaire en forme de vasque, moulurations de type opus sectile de type bandeau, en rinceaux (fig. 10) et gravé, témoignant ainsi d'une grande richesse décorative pendant la dernière phase médiévale, concentrée dans l'espace du cœur.

Fig. 10 - Zone 1B. Église. Bords d'encadrements et tables et (1904) rinceaux.

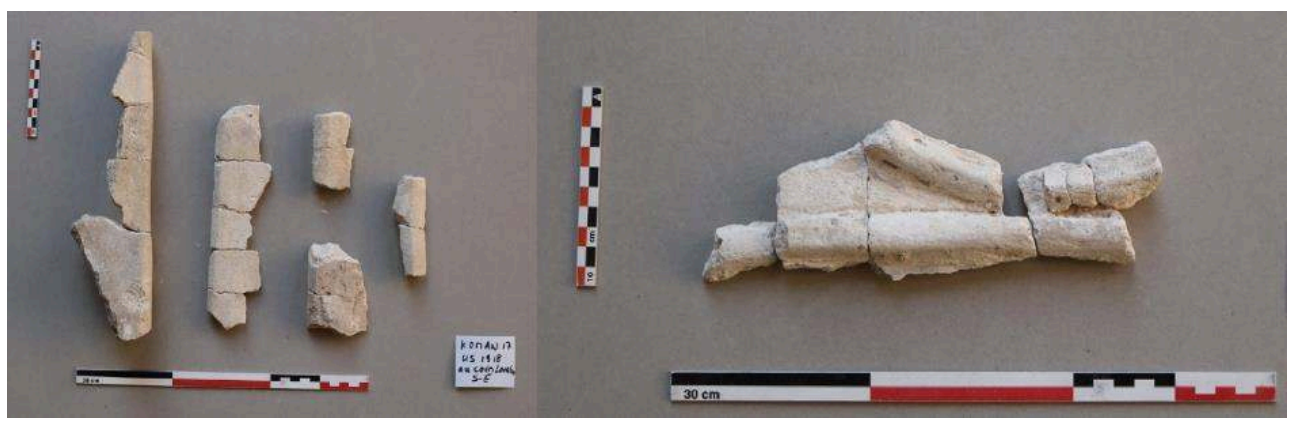

Cl. W. Boutenbat.

12 De très nombreux fragments d'enduit peint ont pu être regroupés, restituant au moins huit motifs différents, renvoyant à des éléments de vêtements (motifs perlés et floraux) (fig. 11), lignes et rectangles, fragments de fourrures, motif avec main et gouttes blanches sur fond jaune, fragments de visages humains, inscriptions, etc., le tout provenant fort probablement de la couche la plus tardive d'enduit peint, étalé sur les parois des murs de l'espace sacrée, dont le plus concentré sur le mur nord et l'apside.

Fig. 11 - Zone 1B. Divers motifs sur l'enduit peint des murs de la nef de l'église.
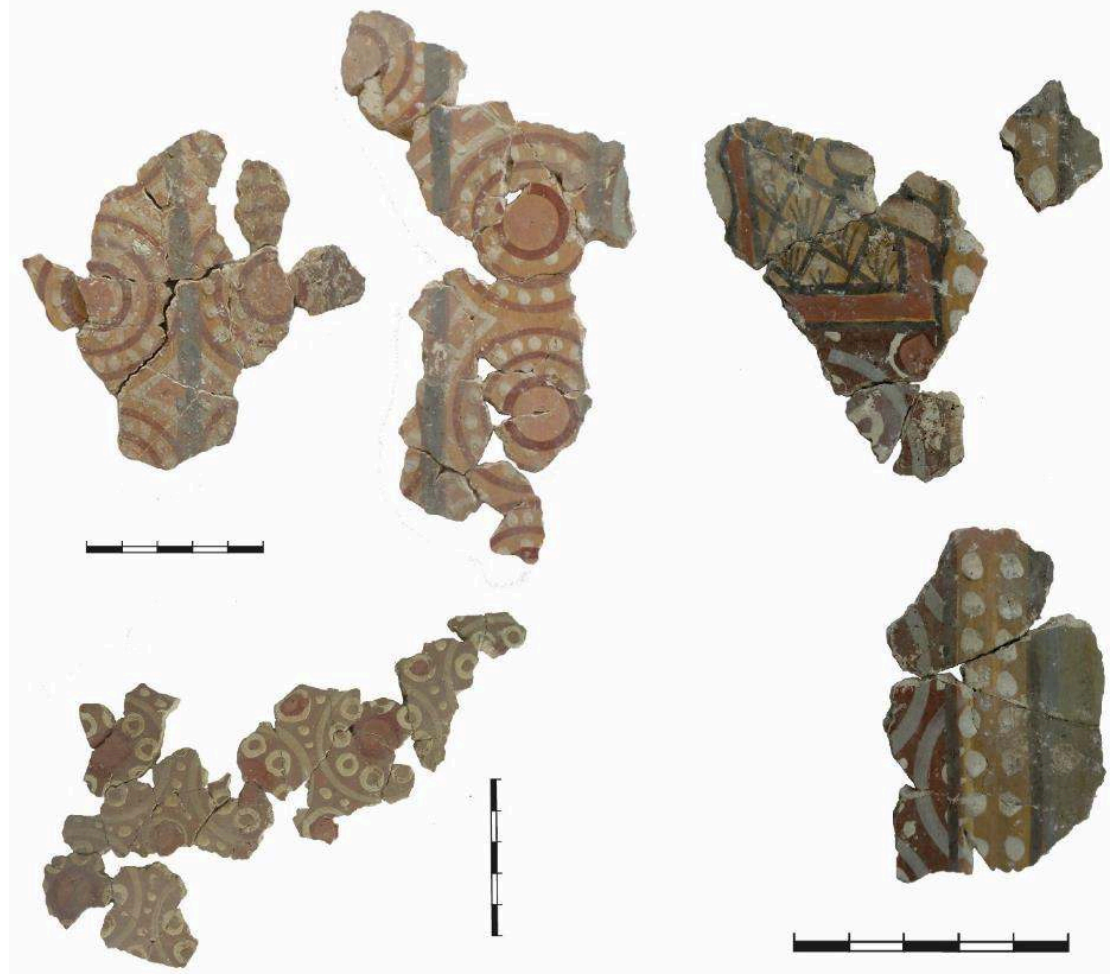

Cl. E Nallbani. 


\section{Objectifs de la campagne 2019}

\section{liturgiques ;}

- définir au moyen d'un grand sondage sur toute la longueur de la nef, englobant le mur nord qui la sépare du collatéral nord, la chronologie de l'église primitive pour comprendre ensuite les différentes phases de remaniements ;

- relever à la photogrammétrie, l'ensemble des vestiges de l'église, pour avoir un maximum d'informations, avant l'engagement $d u$ grand sondage. Les installations liturgiques du cœur datant l'époque médiévale, sont particulièrement importantes à relever. Elles risquent à disparaitre par l'engagement de la fouille à la découverte de l'église primitive et des niveaux successifs (rappelons que déjà six niveaux de sols, ont pu être identifiés par petit sondage au centre-sud de la nef) ;

- fouiller l'inhumation identifiée au centre de la nef de l'église (en 2016);

- précisant les rapports typo-chronologiques entre les bâtiments de ce secteur, entre l'église, les sépultures du chevet et le bâtiment rectangulaire, par un grand sondage à l'est du chevet de l'église ;

- fouiller l'espace à l'ouest de l'église, afin de vérifier sur l'existence d'un narthex, ou tout simplement appréhender l'organisation de la plateforme devant l'entrée. Ces opérations qui à l'origine étaient envisagées en deux campagnes, nous les avons réalisées en une seule consistante 2019.

Après quatre semaines d'intenses opérations de fouilles à l'intérieur de l'église et de son entourage immédiat, les résultats principaux ont permis de reconnaitre un bâtiment qui ne semble pas avoir subi d'altération extérieure de sa forme ou d'agrandissement. Sa complexité s'exprime uniquement dans l'aménagement de l'espace intérieur, où on distingue plusieurs états et plusieurs phases qui correspondent à des travaux menés dans un seul bâtiment. On a pu identifier 5 états principaux (fig. 12), où les changements à observer touchent plutôt la moitié est de la nef, l'espace sacré. 
Fig. 12 - Zone 1B. Proposition de mise en relation des différents états de l'église 2019.
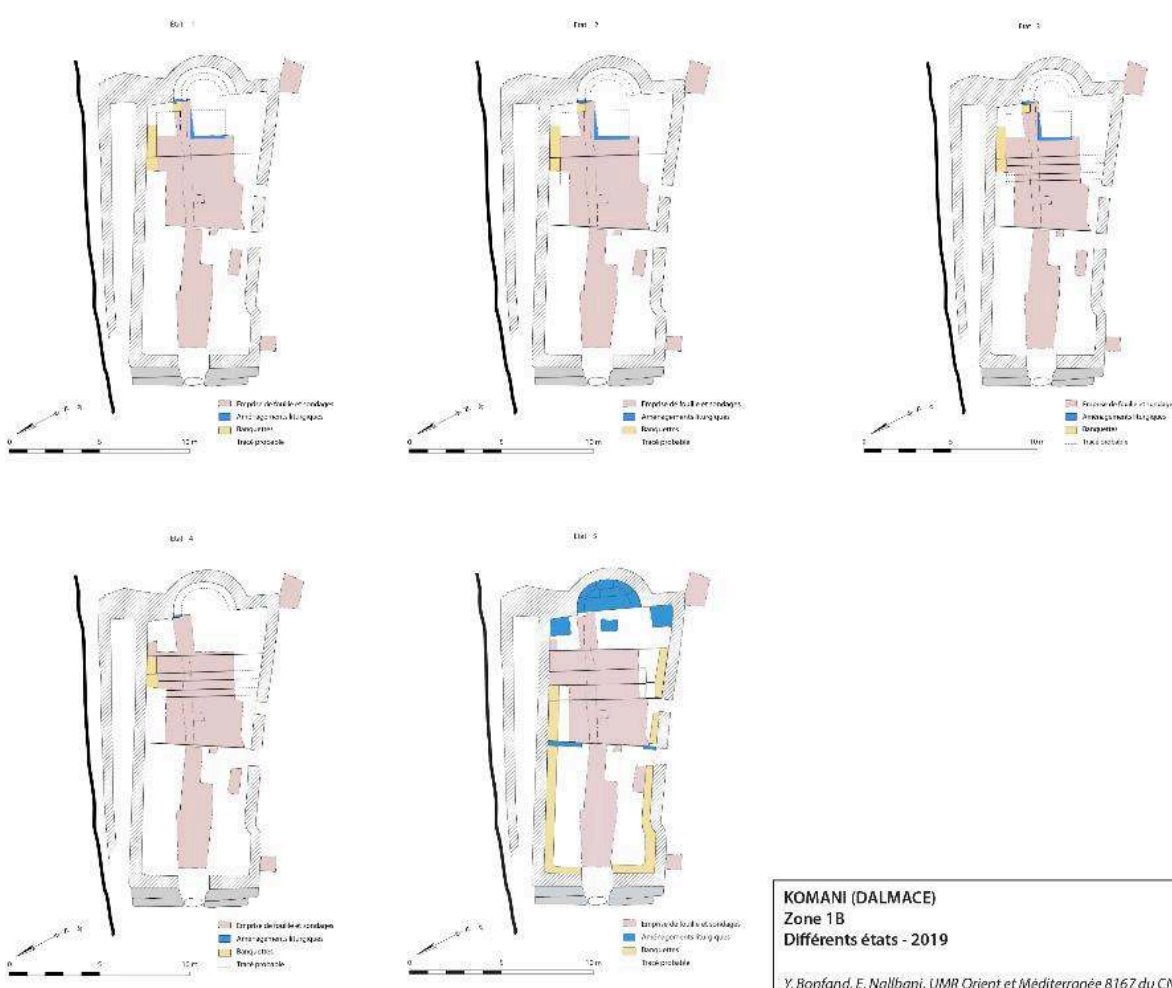

KOMANI (DALMACE)
Zone 1B
Differents états - 2019
Y. Bonfand, E. Nallbani, UMR Orient et Mediterronée 8767 du CNRS/EFR/A

(c) Mission archéologique «Basse vallée du Drin », DAO : Y. Bonfand, E Nallbani.

16 Les éléments plus importants découverts dans cet espace sont: un autre système de marches antérieur (fig. 13) (à plusieurs niveaux d'interventions ayant un rôle sur la profondeur et la hauteur), conduisant vers le cœur, un podium sous le soubassement du positionnement de la table d'autel médiéval et une banquette, un premier synthronon sous celui de la dernière phase apparente qui contourne l'apside.

Fig. 13 - Zone 1B. Église. Marches 1980-1981-1943-1944 en cours de fouille.

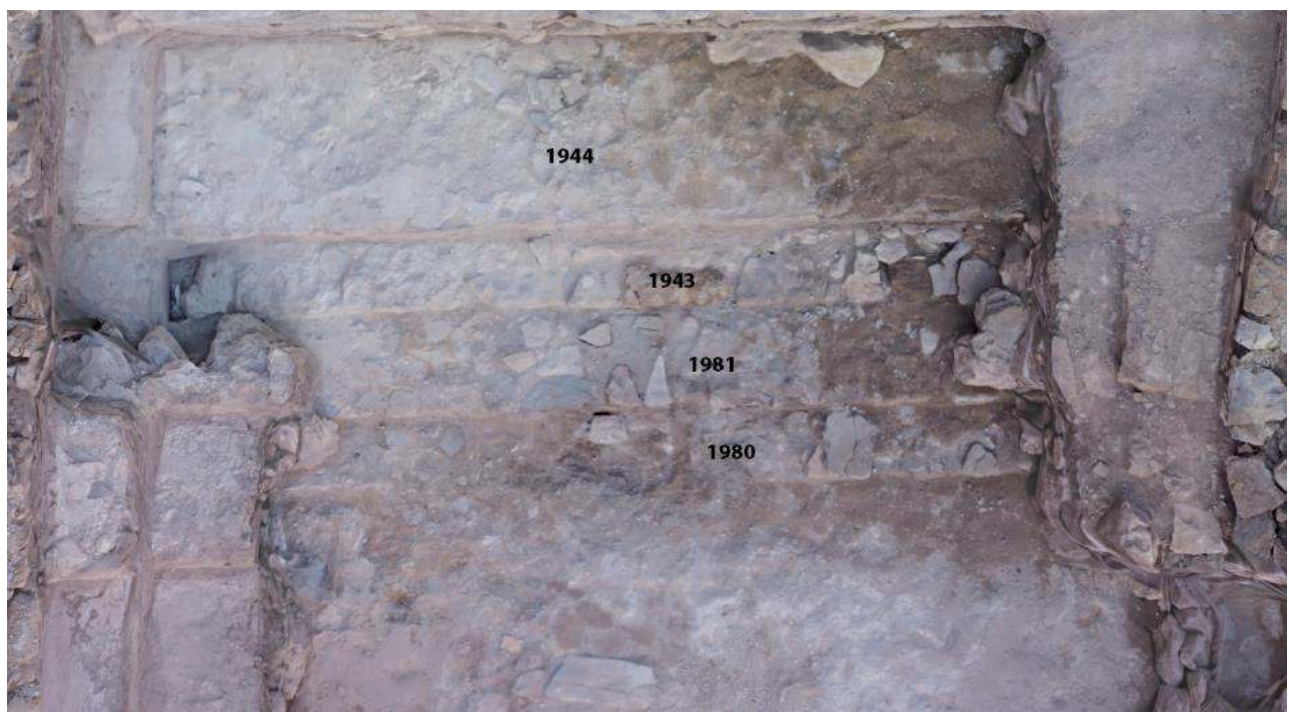

Photogrammétrie : Y. Bonfand. 
17 En effet, si on présentait tous ces éléments dans l'ordre d'une chronologie relative, on aurait une église désaxée dès son origine (voir état 1 dans fig. 12) avec sol de mortier qui de l'entrée principale aboutit à une marche profonde [1996] (fig. 14-15) installée pour constituer un espace spécifique au niveau du chœur, contrainte par le substrat non aplani pour l'édification du monument. Cette marche-plateforme qui occupe le quart de la longueur de la nef, reçoit par la suite un ensemble d'aménagements liturgiques, tous construits en pierres et mortier et entièrement couvert d'une couche très fine d'enduit beige de très bonne qualité :

- un banc [1986], composé d'une seule marche visible, haut de 0,47 $\mathrm{m}$ et large de 0,38 m, et bien conservé, épouse la courbure absidiale, telle qu'elle est observée à l'angle nord de l'abside, grâce au sondage consistant [11011] (fig. 16). Ce sondage se limitant au dégagement d'une coupe au droit des aménagements, il nous a été impossible de déterminer s'il s'agit d'une simple banquette ou d'une composition hiérarchisée équivalente au synthronon médiéval (des mêmes dimensions) qui lui est superposé (fig. 17). Ce premier synthronon est précédé par une marche [11005], observée sur $0,30 \mathrm{~m}$ de longueur et $0,27 \mathrm{~m}$ de hauteur ;

- une banquette [1995] (fig. 18) qui mesure 0,24-0,26 $\mathrm{m}$ de hauteur pour environ 0,30 $\mathrm{m}$ de largeur, prend appui contre le banc absidial et se poursuit contre le mur nord-est (M48) de la nef, sur 0,30 m observés. L'installation liturgique de la phase médiévale, dans cet angle de la nef, empêche de vérifier sa prolongation vers l'ouest. Fort probablement elle joint la banquette 1931, contre le mur nord, fouillée en 1917. Si tel est le cas, aucune circulation ne serait, de fait, possible avec le collatéral sans considérer une utilisation de la banquette comme marche ;

- un podium rectangulaire (l'US 1989 de 1,50 m E/O × 1,80 m N/S et 0,15-0,20 $\mathrm{m}$ de haut) repose sur la couverture en mortier [US-11002] de la marche 1996, occupant la partie centrale et aligné avec elle (voir fig. 14). Le podium retenait fort probablement un autel, dont son existence reste hypothétique, à cause de la largeur réduite du sondage 11011 (fig. 19). 
Fig. 14 - Zone 1B. Église. Marche 1996 au fond du sondage 11011.

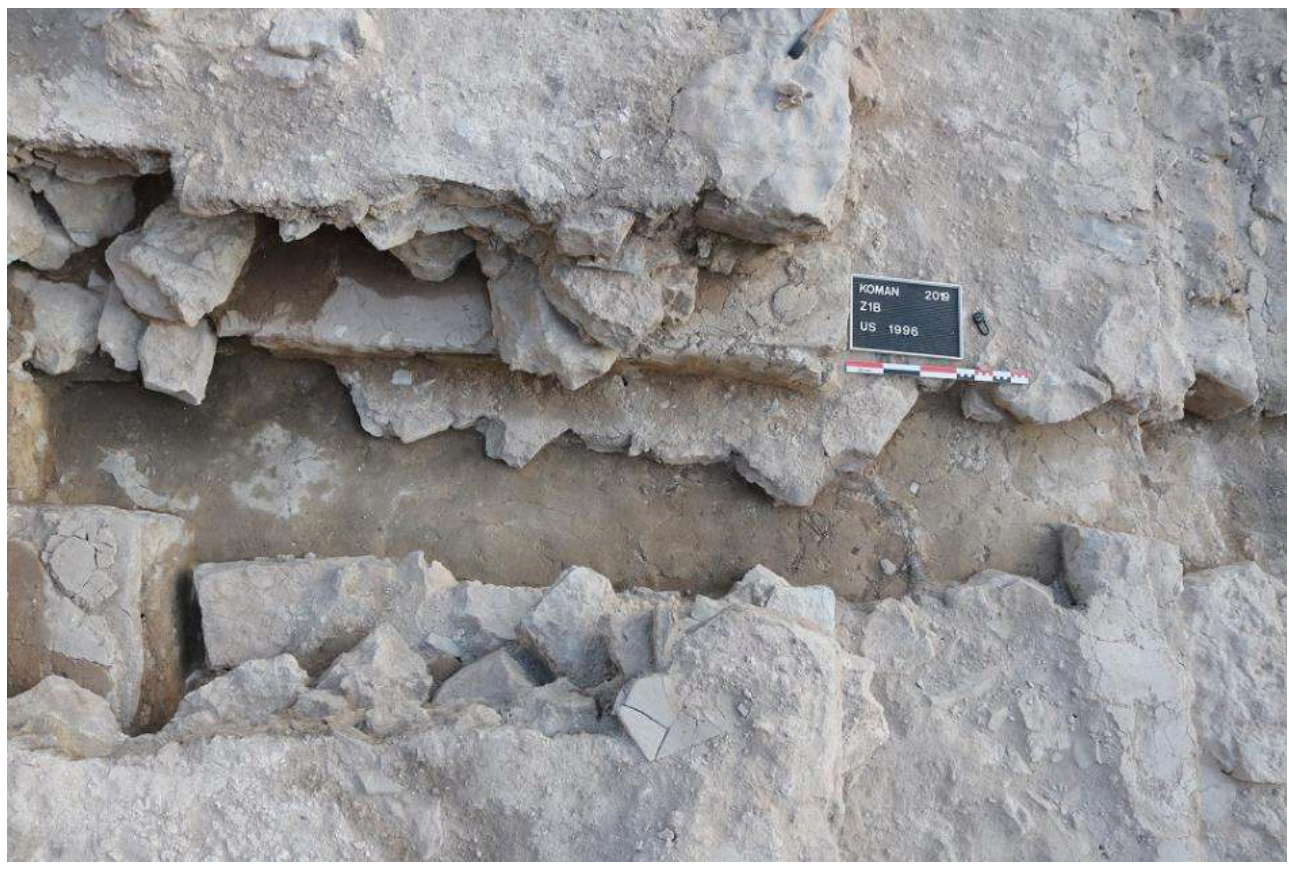

Photogrammétrie : Y. Bonfand.

Fig. 15 - Zone 1B. Église. Coupe transversale de la nef, différents états - 2019.

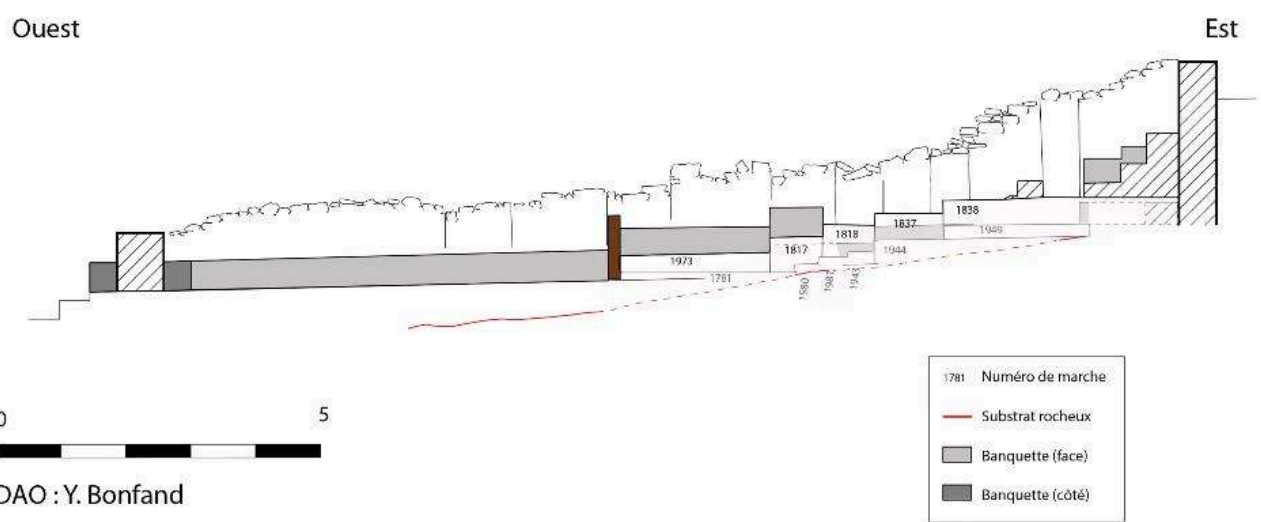

DAO : Y. Bonfand. 
Fig. 16 - Zone 1B. Église. Banc absidial 1986 sous le synthronon lors de la découverte dans le sondage 11011 .

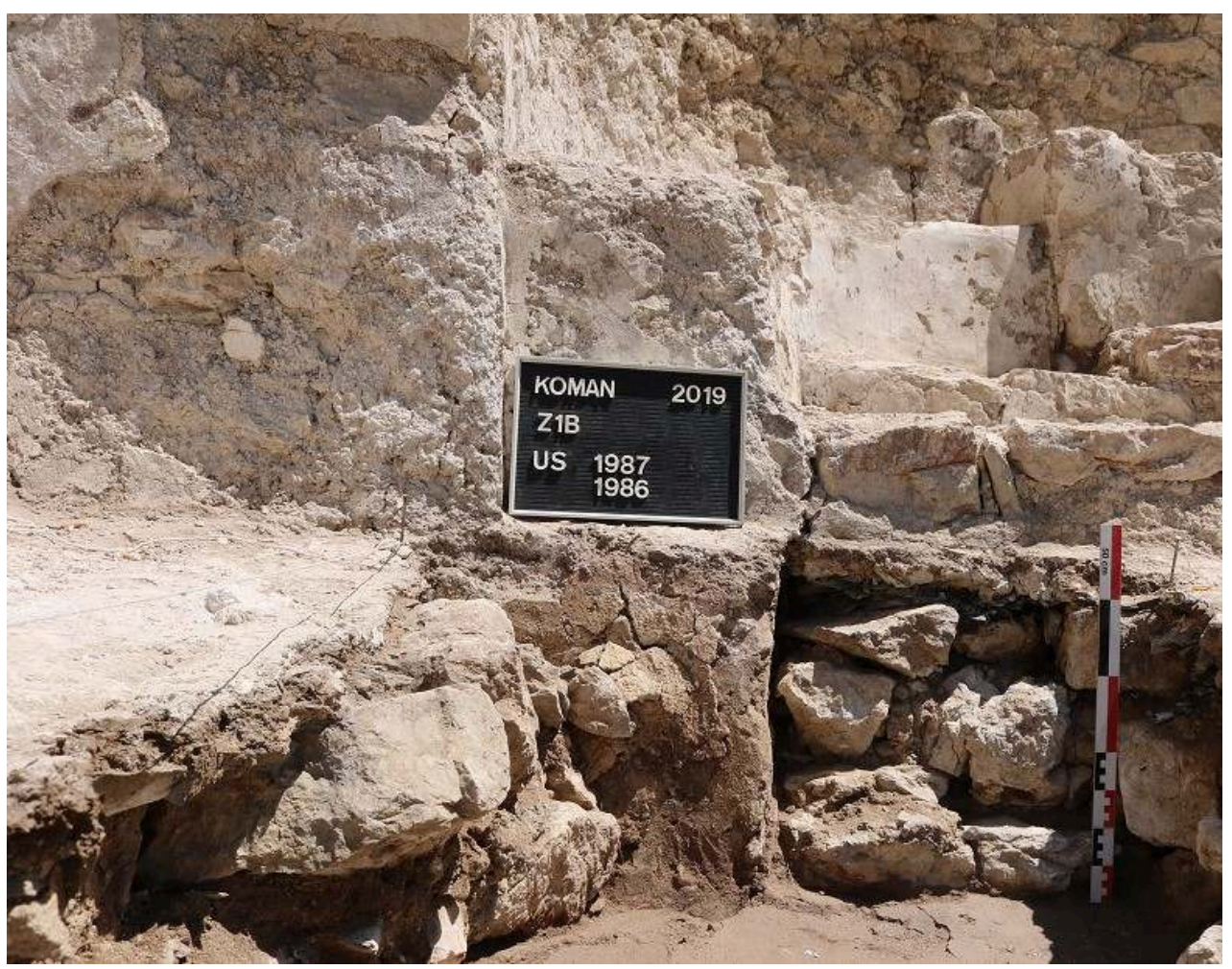

Photogrammétrie : P. Mollard. 
Fig. 17 - Zone 1B. Église. Superposition du synthronon et du banc absidial 1986. Vues en plan, de face et de biais avec le sondage 11011 .
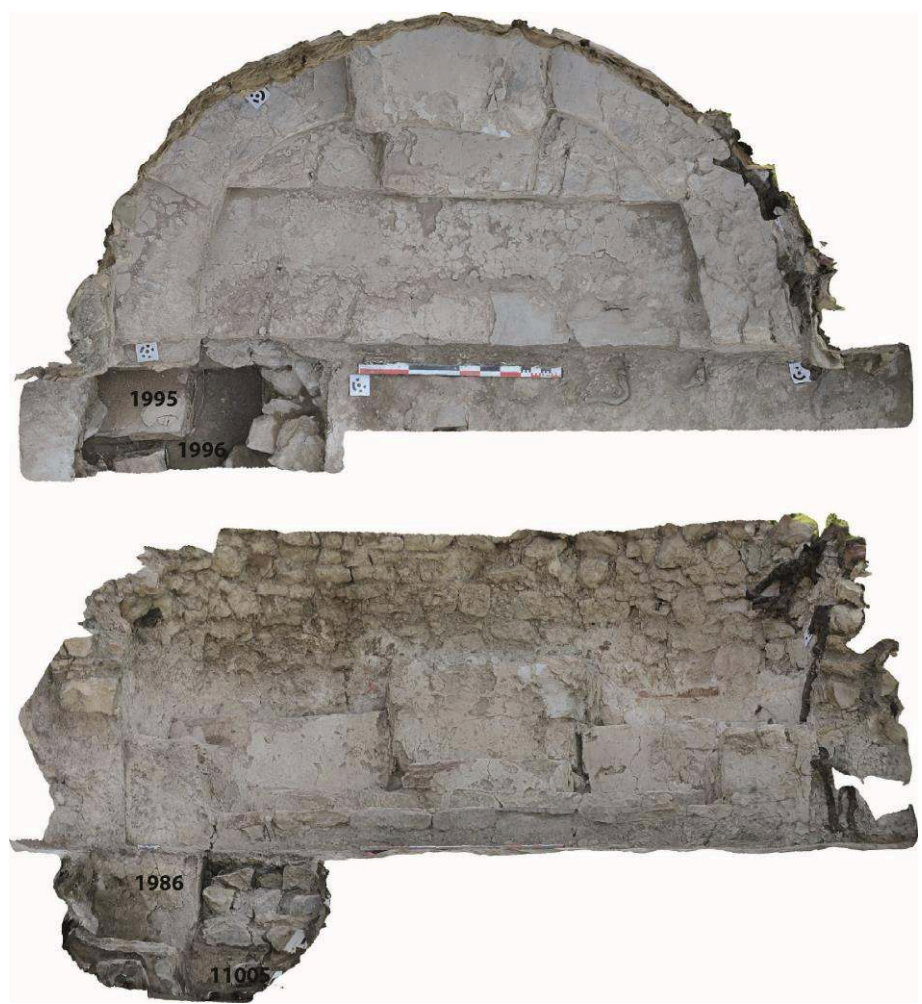

Photogrammétrie et orthophoto : Y. Bonfand.

Fig. 18 - Zone 1B. Église. Banquette 1995 adossée contre le banc absidial.

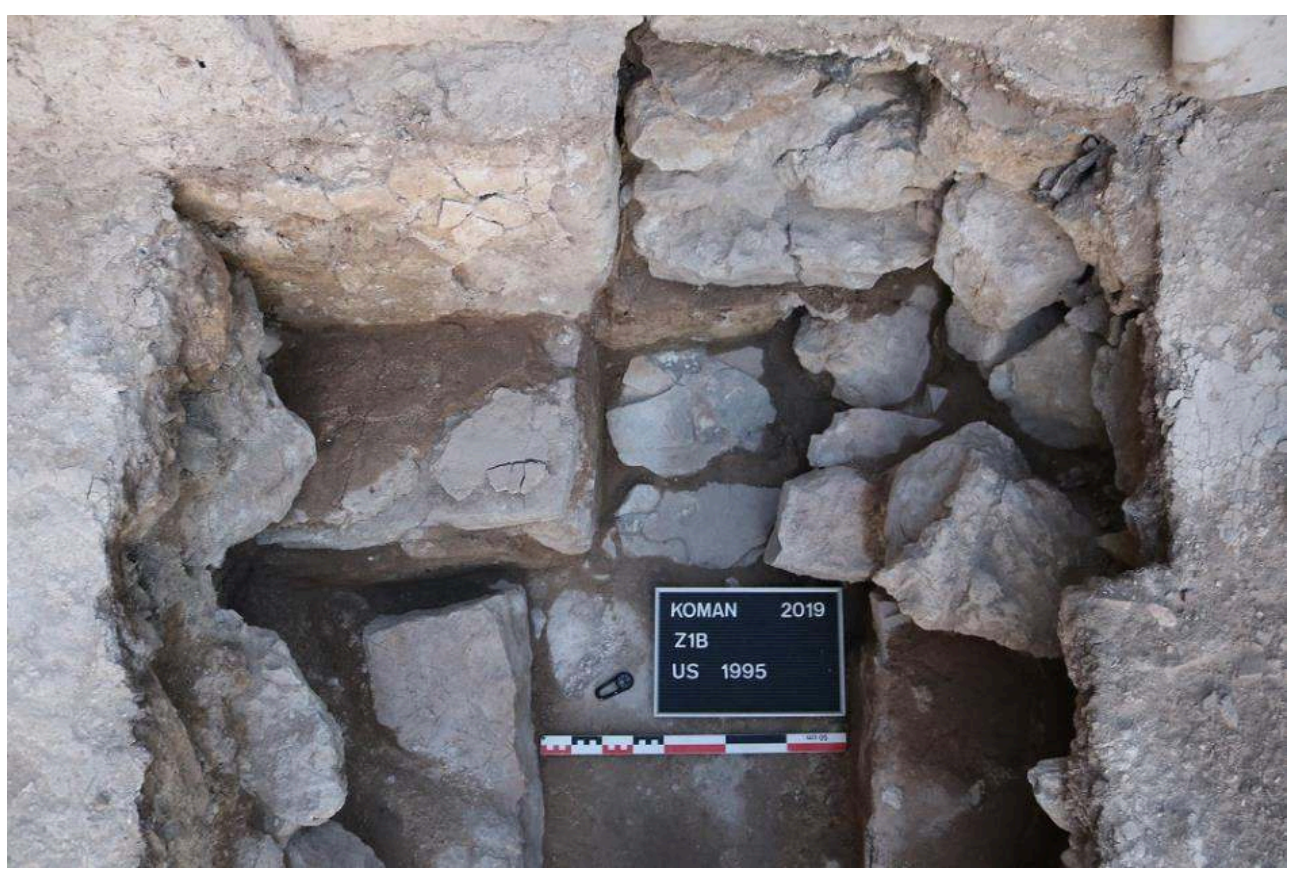

Cl. P. Mollard. 
Fig. 19 - Zone 1B. Église. Podium 1989, angle nord-ouest.

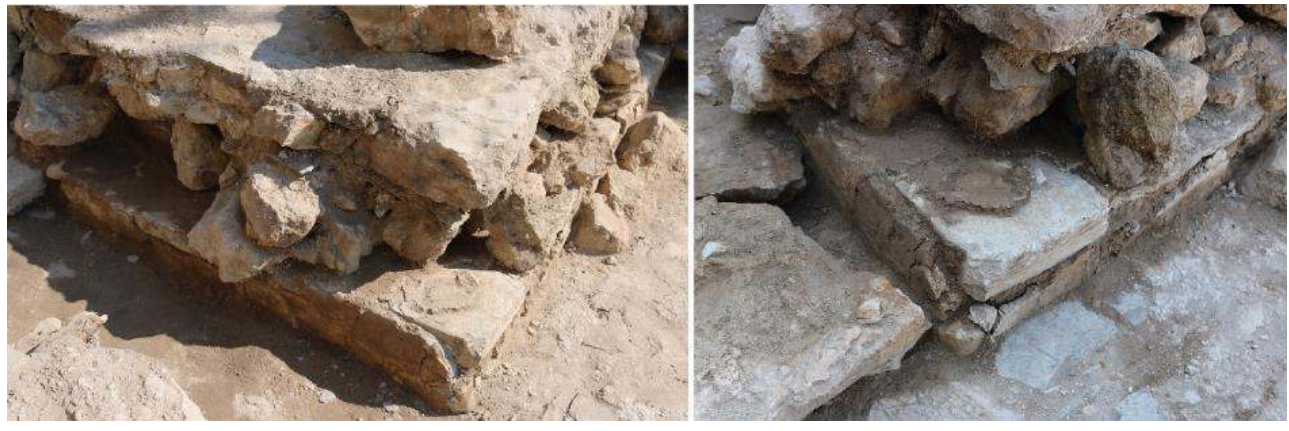

Cl. Y. Bonfand.

18 L'apside a été déjà peinte (fig. 20), ainsi que le double pilier dans le mur nord, avec la scène figurée avec le cerf (voir fig. 3). Ce double pilier fonctionne avec les banquettes au nord et avec le premier état de l'église.

Fig. 20 - Zone 1B. Église. Enduits peints de l'abside.

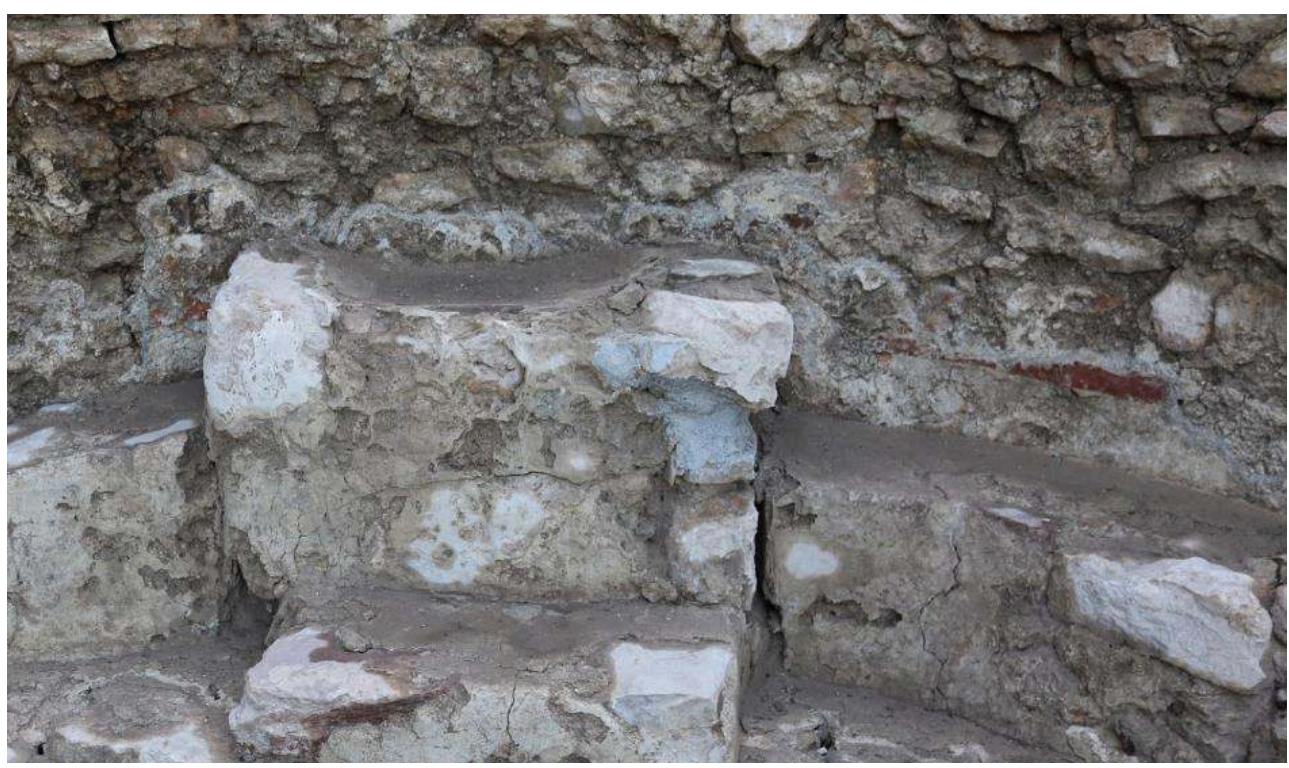

Cl. E. Nallbani.

19 Dans un second état (voir fig. 12-15), pour des raisons probablement de stabilité du bâtiment, une autre marche-plateforme s'installe au milieu de la nef [1781], qui permet de briser le pendage de la nef et de créer un premier palier avant la marche 1996 (fig. 21). Elle est alignée avec la porte sud et repose directement sur un niveau de sol [1782] (fig. 22). A l'instar de toutes les autres marches, la 1781 est constituée de blocs disposés en une assise et d'un comblement de pierres et dalles disposées avec soin à plat. 
Fig. 21 - Zone 1B. Église. Marche 1781 après retrait de la marche 1973.

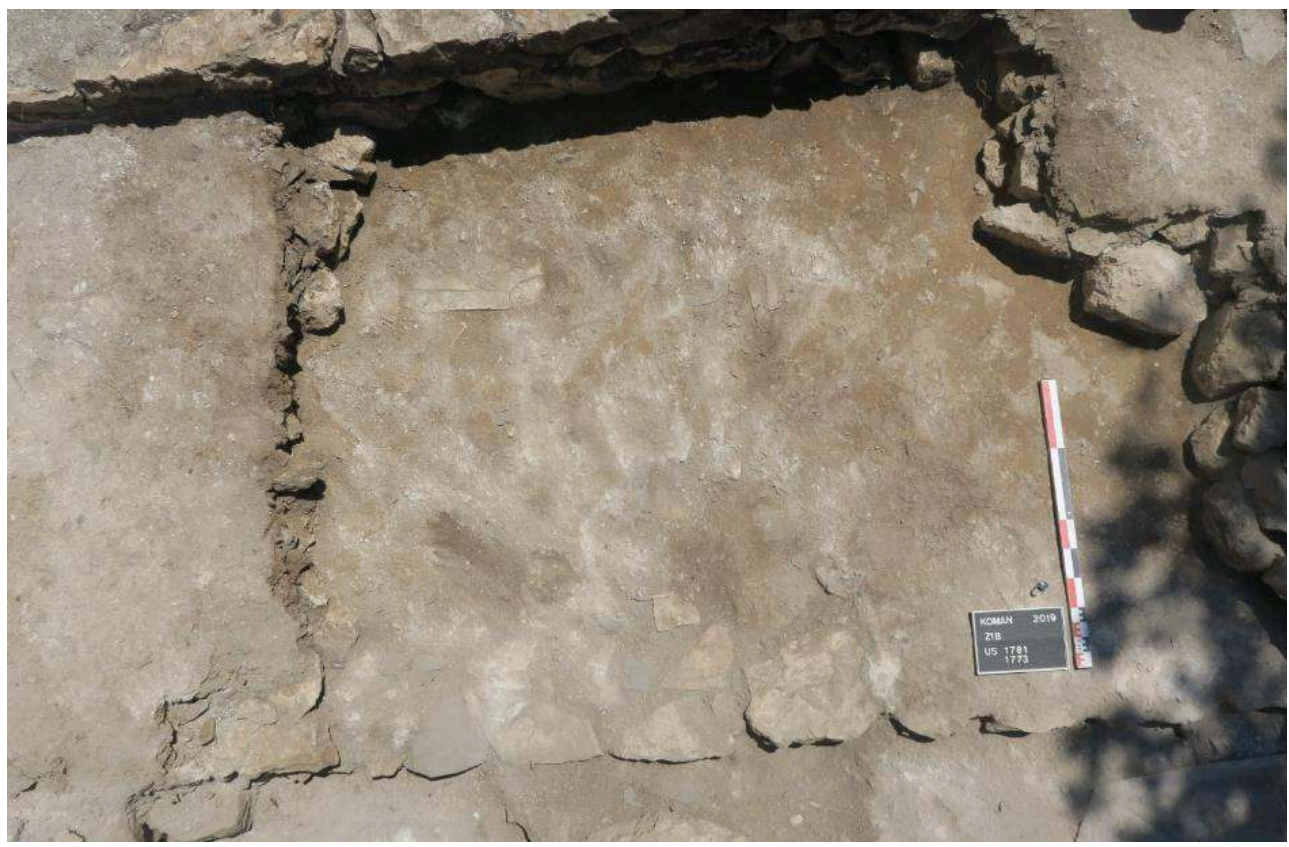

Cl. Y. Bonfand.

Fig. 22 - Zone 1B. Église. Sol 1782 sous la marche 1781.

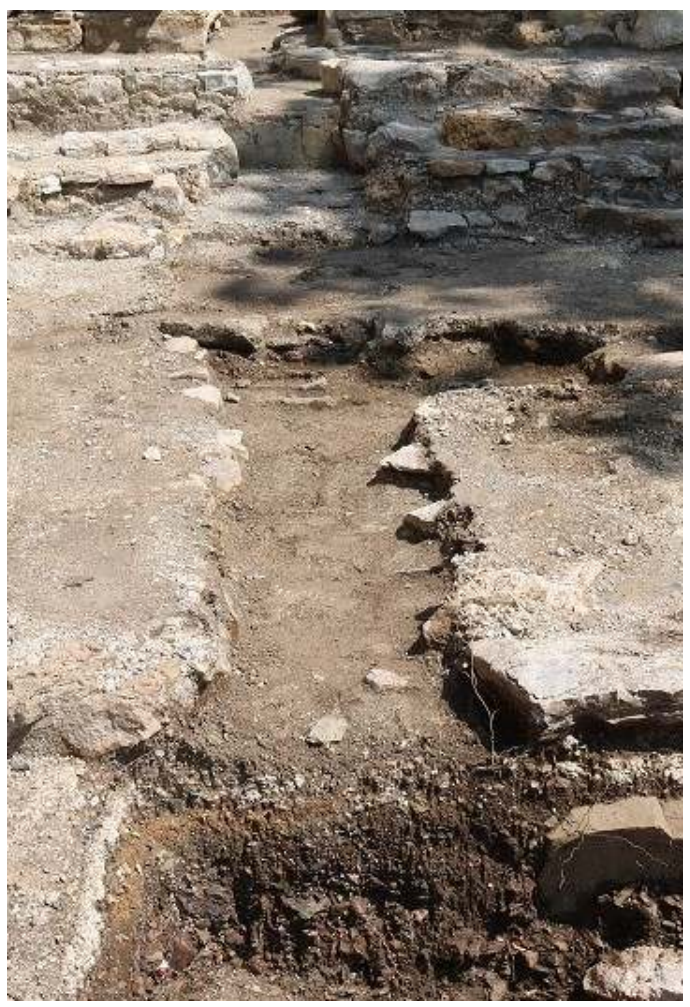

Cl. Y. Bonfand.

Un troisième état (voir fig.12-15) de l'intérieur de l'église connait un premier rehaussement par l'ajout de trois marches intermédiaires entre 1781 et 1996 (voir fig. 13). Quoique relativement peu élevées, elles n'en nécessitèrent pas moins de 
surélever la plateforme 1996, par le rehaussement 1944, compensant son pendage d'environ $0,14 \mathrm{~m}$. Ces marches sont en partie construites avec des blocs de tuf taillés, attestant de destructions ou reprises de l'église voire d'une structure attenante. La volée de marches qui se succédaient ainsi visait à surélever le chœur et l'abside de l'église. Elles ont perturbé ponctuellement l'utilisation des banquettes qui n'ont certainement pas été altérées à ce moment. Le podium construit afin de compenser le pendage, a ainsi perdu une partie de son élévation sur son côté ouest, mais bien moindre de l'autre côté. Il fut recouvert d'une nouvelle couche de mortier qui englobait toute la marche.

21 Pendant le quatrième état (voir fig. 12-15), ces trois marches de l'ouest vers l'est, ont été gardées, mais la moitié ouest de la plateforme du chœur, transformée en rajoutant une quatrième marche [1949] (fig. 23) qui a diminué la largeur de la nouvelle plateforme. Par conséquent l'ancien podium de l'autel est condamné et pris dans la nouvelle plateforme surélevée de $17 \mathrm{~cm}$, comme par ailleurs la banquette en L, de l'angle nord-est de la nef et la marche du banc absidial qui disparaissent (fig. 24). Le tout est couvert d'une couche d'enduit blanc.

Fig. 23 - Zone 1B. Église. Extrême nord de la marche 1949 lors de la découverte en 2017.

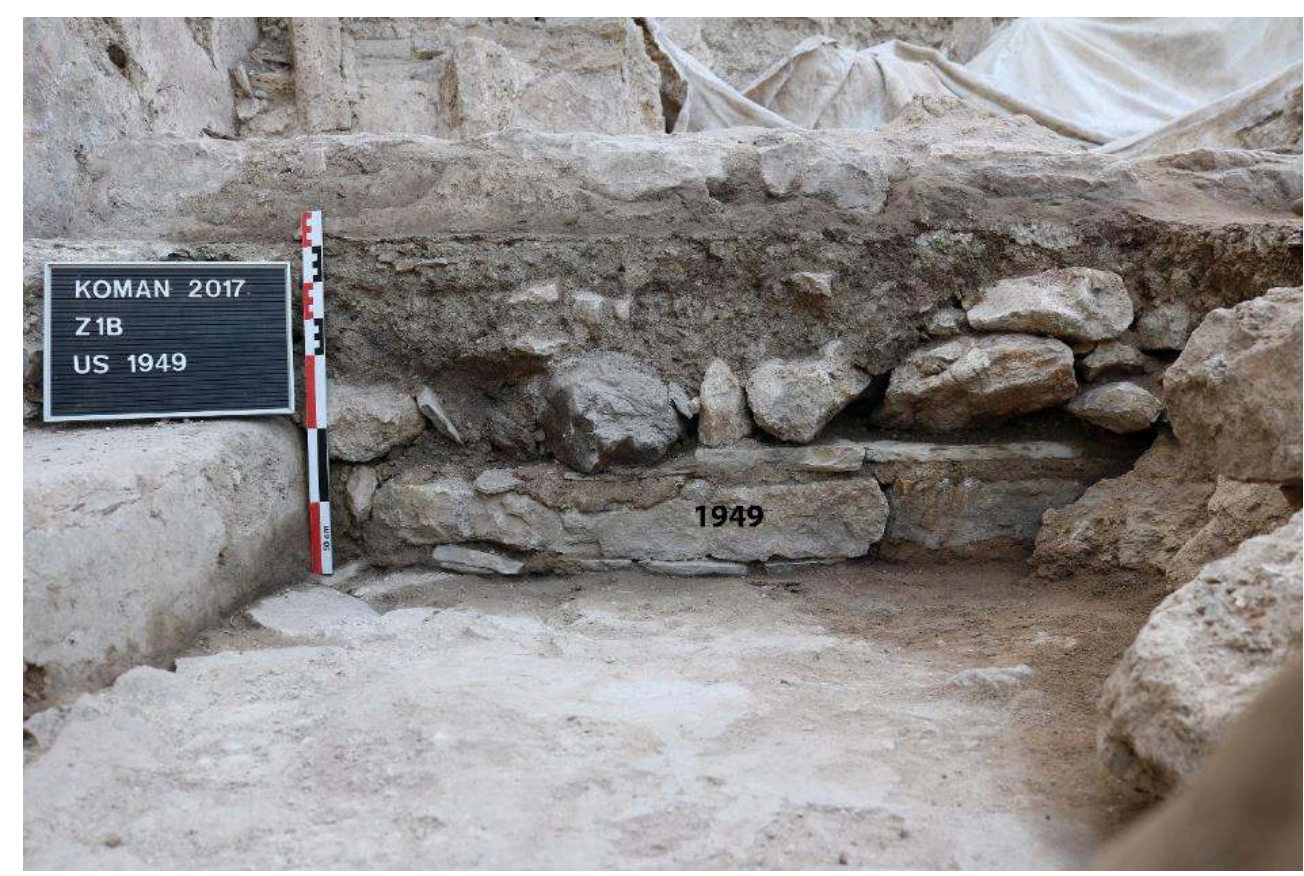

Cl. Y. Bonfand. 
Fig. 24 - Zone 1B. Église. Marche 1949, rajoutée sur la plateforme du cœur, condamnant l'ancien podium.

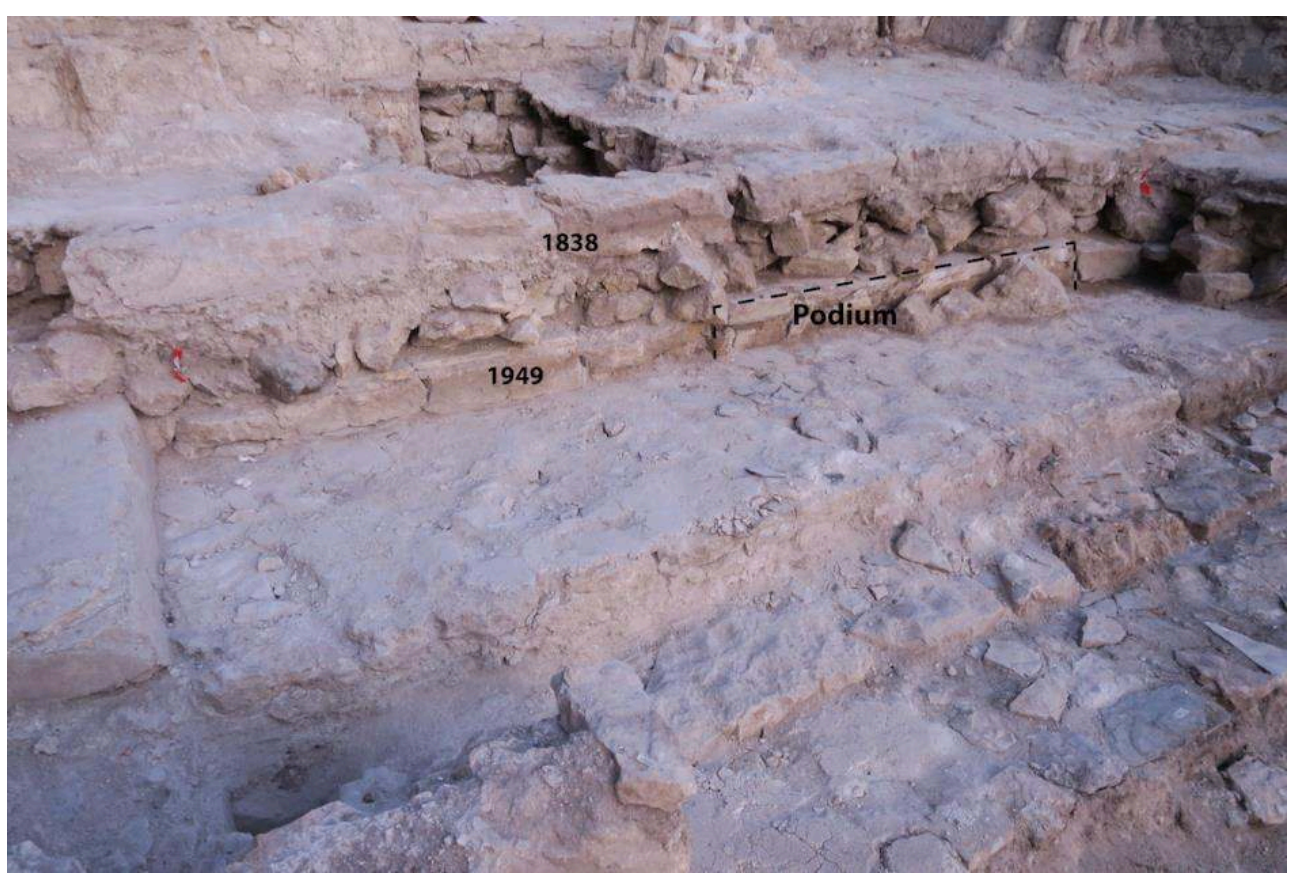

DAO : Y. Bonfand.

Aucun aménagement liturgique n'est connu pour cette phase. Aucun élément ne permet de comprendre les raisons de cette altération qui a essentiellement visé à supprimer le podium qui avait peut-être perdu de son importance rituelle. Il n'aurait pas été possible de retirer le podium puisque ce dernier repose sur la marche 1996.

Pendant le cinquième état du bâtiment (voir fig. 12-15), après avoir complètement obstrué les ouvertures du mur du collatéral, la moitié est de l'église a été progressivement rehaussé. Une marche 1838 superposée à la 1949 (voir fig. 24), dont le sol vient s'appuyer contre bouchage. La marche intermédiaire 1781 a été rehaussée par 1973 (fig. 25), à qui se rajoute la construction de la structure en tuf, la chancelle (voir fig. 6). Les banquettes nord et sud ont été ajoutée au même moment. Ensuite un rehaussement massif de l'espace jusqu'à l'apside, se fait avec les marches 1817-1818-1837 toutes alignées avec la 1838 (voir fig. 3, 15, 24) et des banquettes s'installent tout autour des murs sud, nord et ouest. De nouvelles installations liturgiques prennent place dans le cœur, telles qu'on les voit, synthronon avec cathèdre, aménagements liturgiques sud et nord et base d'autel. La majorité des fragments d'enduits peint (voir fig. 11), dont une partie assemblée, provient de cette phase, ce qui rajoute au programme global du renouveau architectural de l'église, celui de l'embellissement des murs. 
Fig. 25 - Zone 1B. Église. Rehaussement de la marche 1781 par la marche 1973, en cours de fouille.

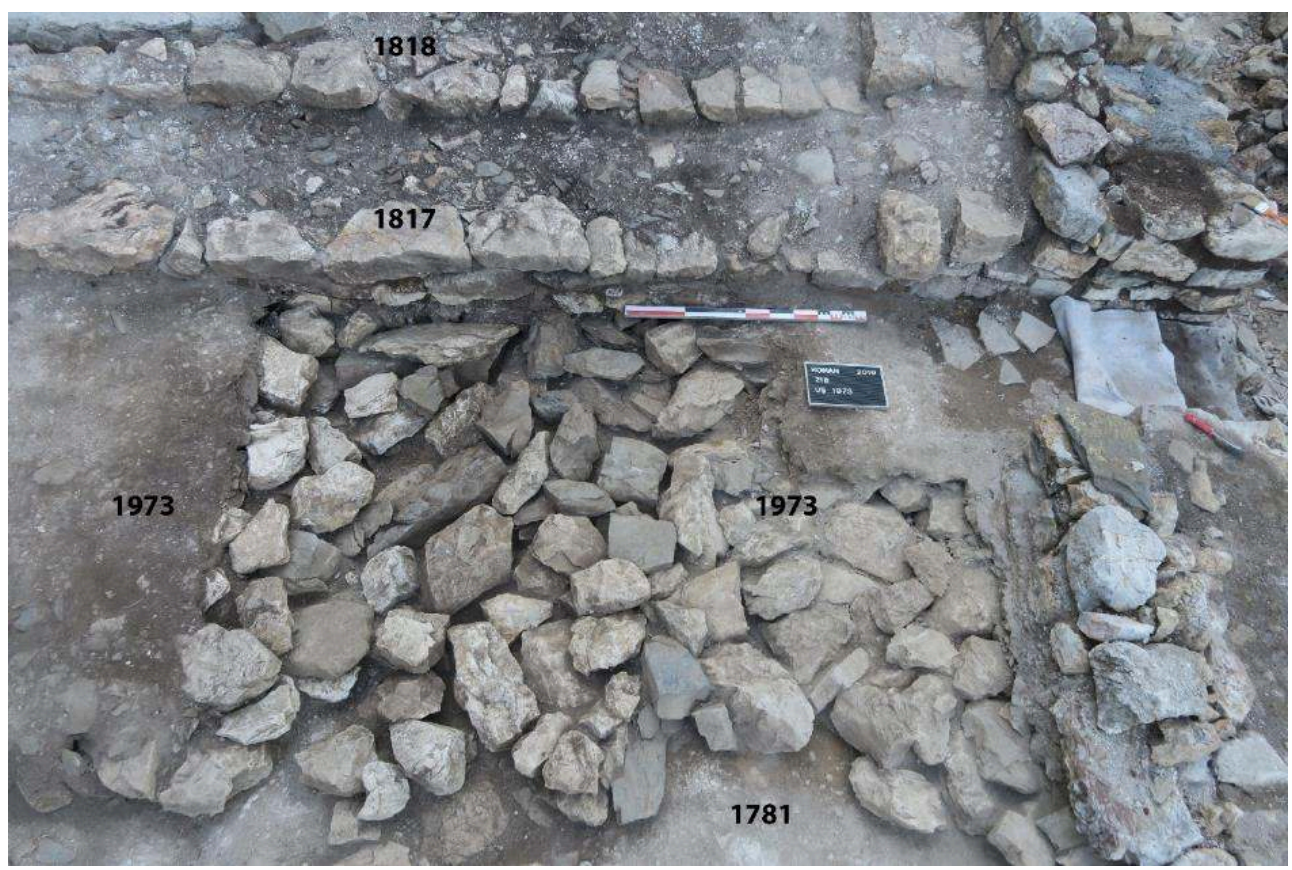

Cl. Y. Bonfand

Un dernier état, voit l'église recouverte d'un enduit blanc qui uniformise l'intérieur et recouvre toutes les aménagements de l'état cinq. L'ensemble de ces transformations, témoigne d'une longue durée de vie pour ce monument et de l'attention reçues en permanence pour servir à la communauté de Komani (fig. 26). 
Fig. 26 - Zone 1B. L'église à la fin de la campagne 2019.

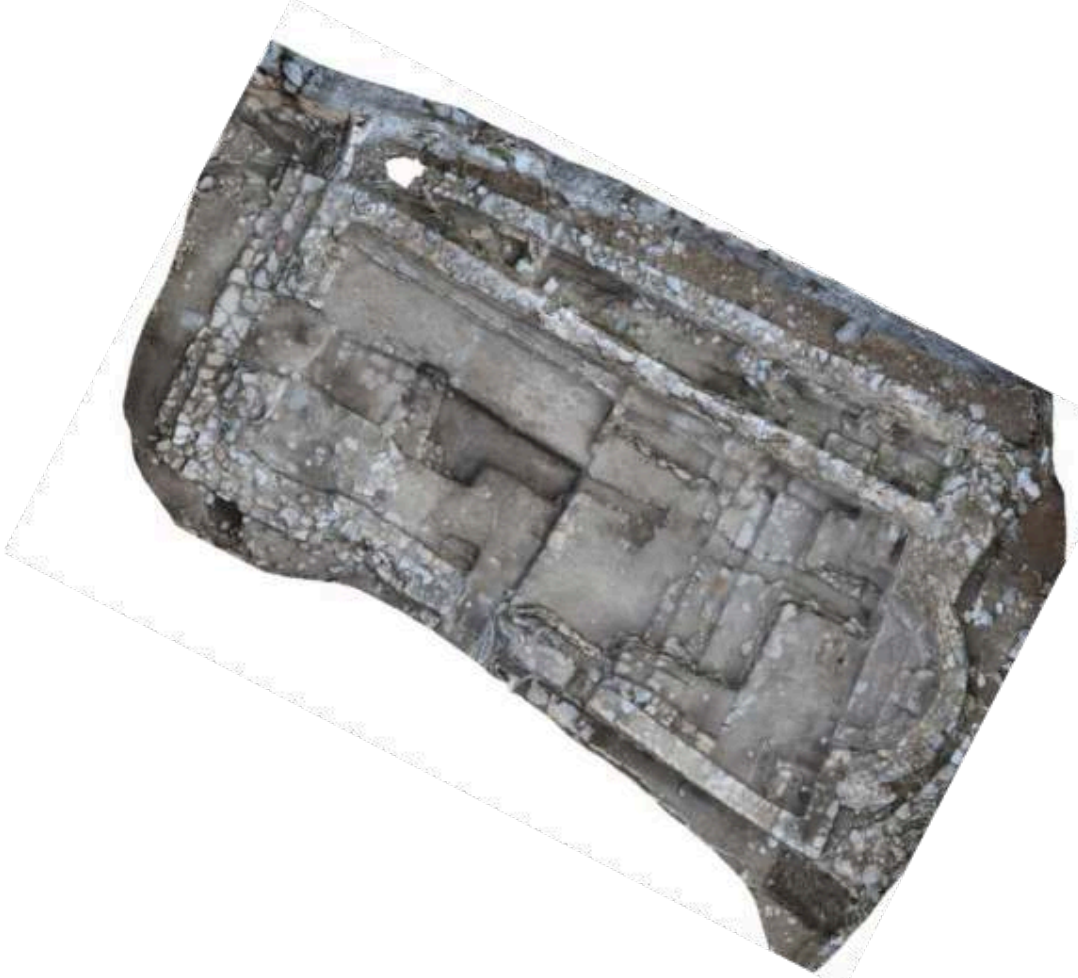

(c) Mission archéologique «Basse vallée du Drin », photogrammétrie : Y. Bonfand.

\section{Structure quasi rectangulaire (11007) dans la nef}

La poursuite du dégagement du sol de la nef a permis de mettre au jour un surcreusement installé dans l'axe de l'entrée principale. Il ne s'agit pas tant d'un seul surcreusement mais de deux formes sub-rectangulaires accolées d'environ $0,15 \mathrm{~m}$ de profondeur (fig. 27). Des rebords qui marquent une séparation entre les deux sont visibles (côté ouest notamment). Enfin, sur le côté sud ont été remarqués d'importants restes de mortier qui recouvrait l'intégralité des parois du creusement. Il s'agit donc d'un aménagement liturgique au sein de l'église qui, à un moment n'aurait plus eu d'utilité et aurait ainsi été comblé de nombreux éléments de destructions et de rejets de maçonnerie parmi lesquels des fragments d'enduits peints de tailles variables (fig. 28). 
Fig. 27 - Zone 1B. Église. Aménagement liturgique (?) 11007, dans la nef, devant l'entrée ouest.

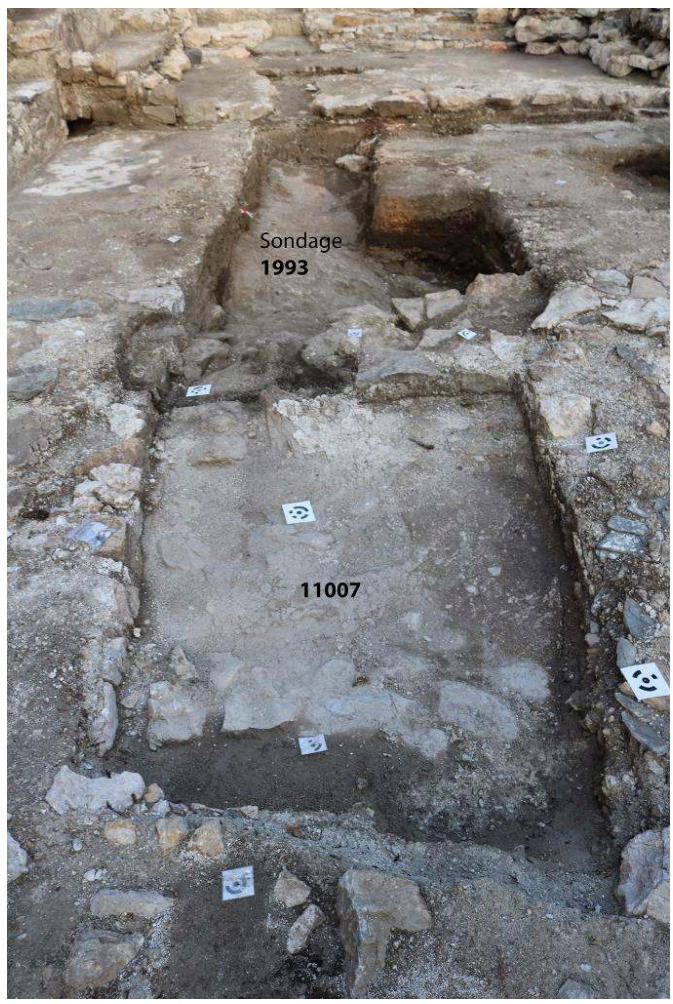

DAO : Y. Bonfand.

Fig. 28 - Zone 1B. Église. Fragments d'enduits peints, provenant de l'aménagement 11007.

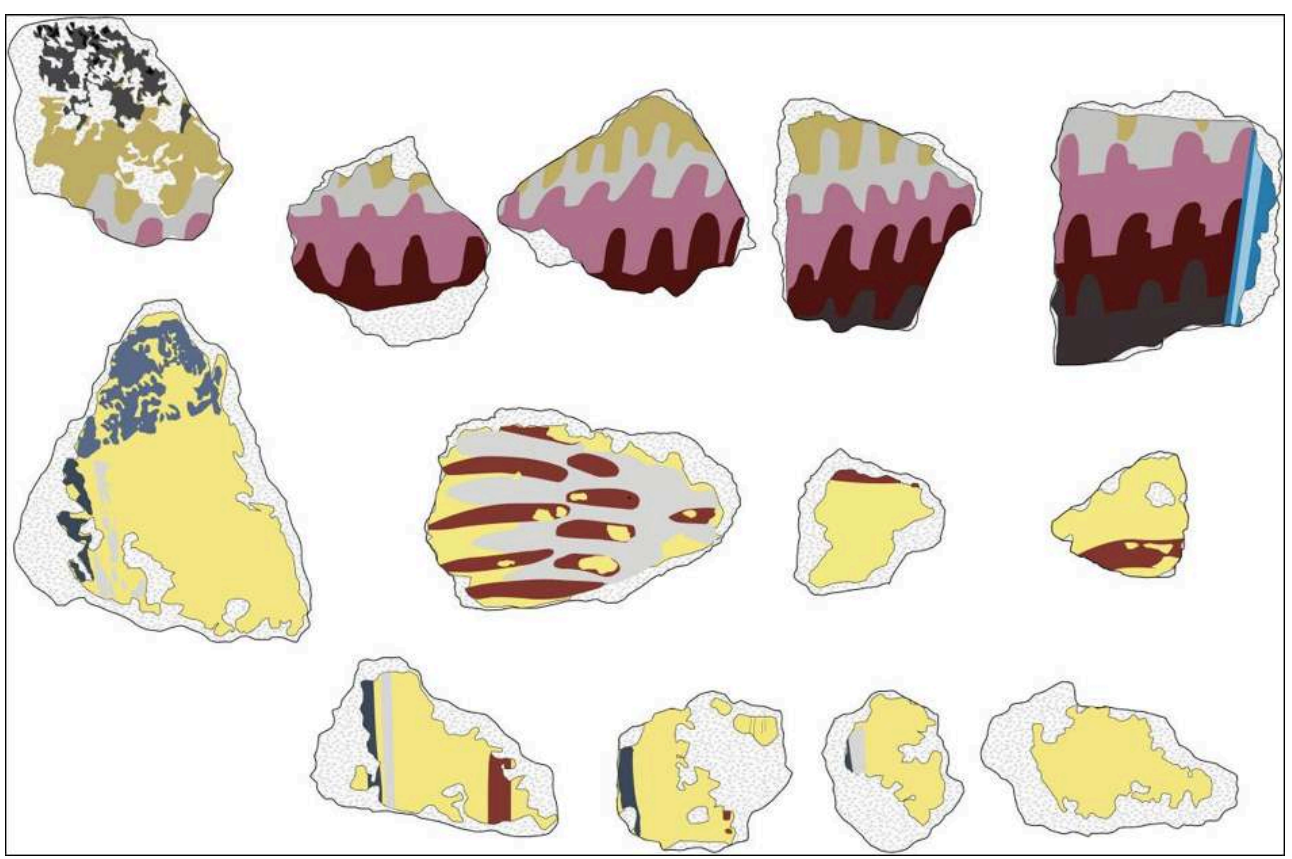

DAO. Y. Bonfand. 


\section{Autres structures plus anciennes dans le secteur}

D'autres découvertes importantes dans ce secteur et en relation avec l'espace de l'église, sous le sol de la nef, sont des fragments de structures maçonnées, désaxées par rapport à l'orientation de l'église, trouvés dans la prolongation du sondage 1993 (fig. 29-30). Elles existaient avant la construction de l'église, dans le secteur 1B (fig. 31 ), ce qui nous renseigne sur l'aménagement précoce de cet espace. Il s'agit uniquement à titre hypothétique, des constructions de l'époque tardo-antique si on juge sur l'appareillage et le liant, similaires aux constructions de la zone $1 \mathrm{~A}$ de l'habitat, attribuées à la première structuration du site, aux $\mathrm{IV}^{\mathrm{e}}-\mathrm{VI}^{\mathrm{e}}$ siècle.

Fig. 29 - Zone 1B. Prolongation du sondage 1993, avec des fragments de structures maçonnées.

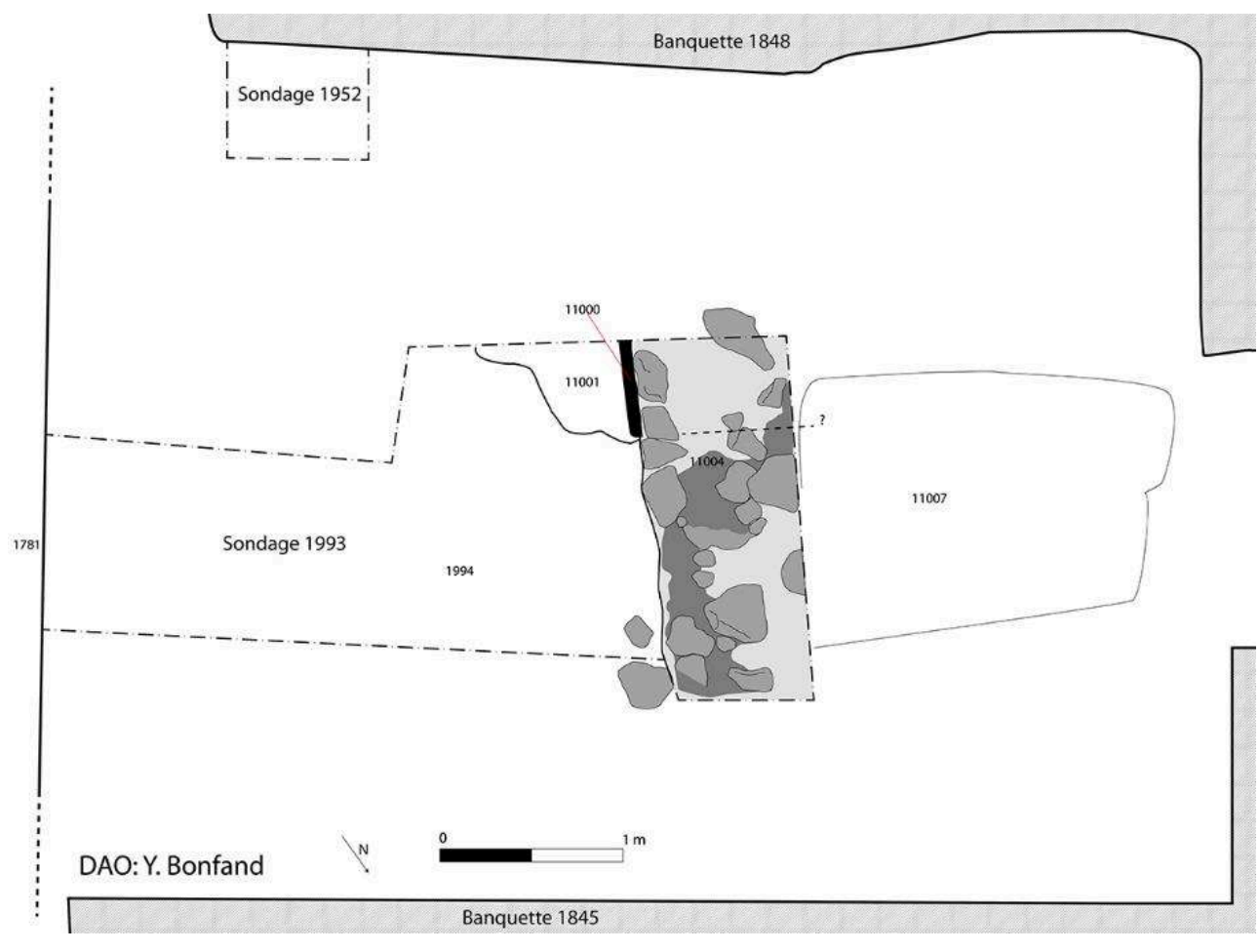

DAO : Y. Bonfand 
Fig. 30 - Zone 1B. Église. Maçonnerie 11000 et remblai 11001.

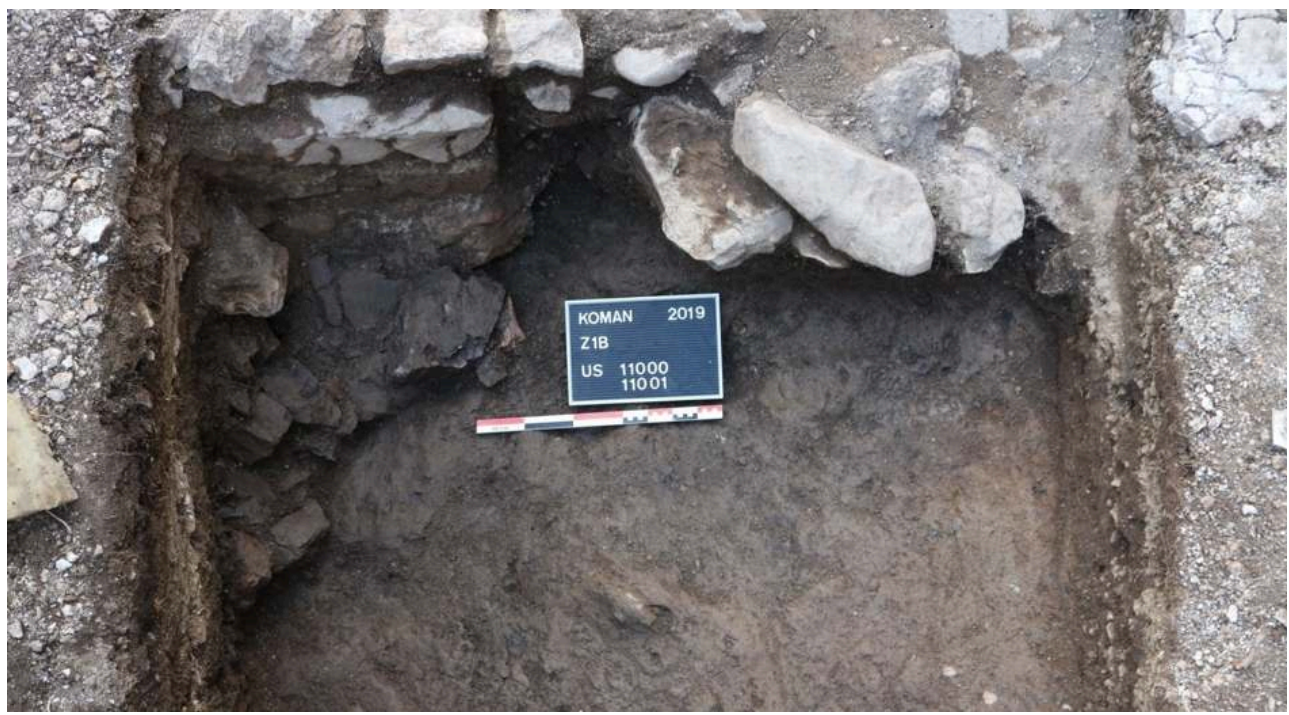

Cl. Y. Bonfand.

Fig. 31 - Zone 1B. Église. Tracé du sondage 1993, avec la mention des structures plus anciennes sous la partie ouest de la nef.

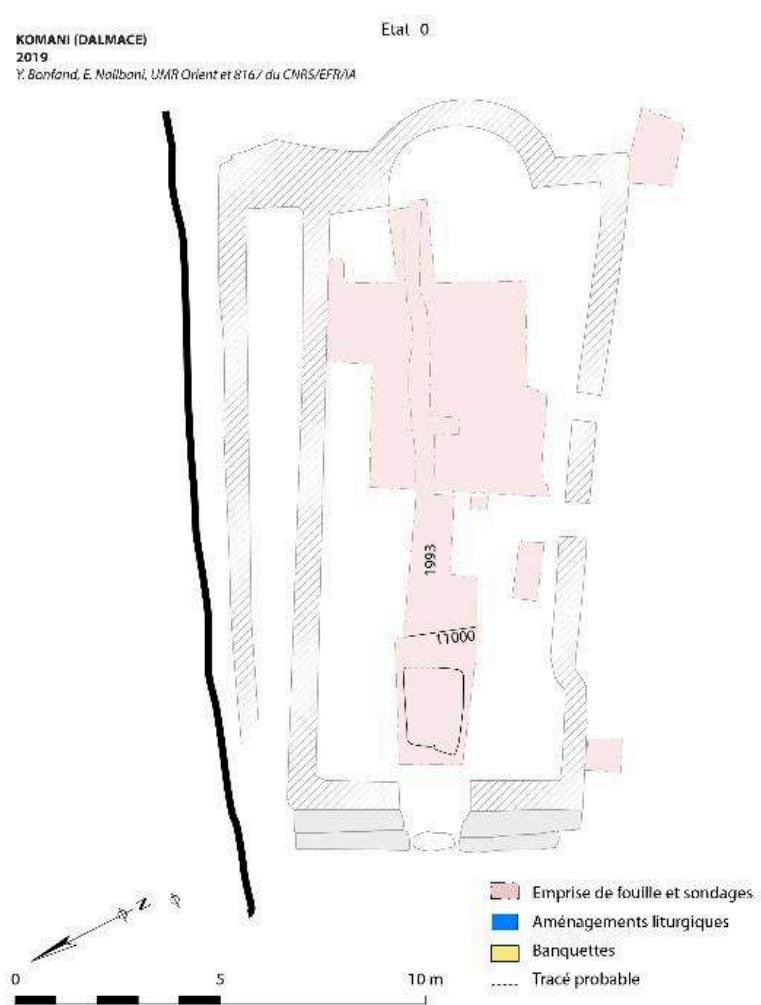

DAO : Y. Bonfand, E. Nallbani.

\section{L'occupation funéraire de l'église}

L'église a livré également un aspect funéraire encore plus riche que supposé. Outre les 11 sépultures, installées dans l'annexe nord et les 13 installées derrière le chevet, toutes mises au jour pendant les campagnes précédentes, une inhumation (T389) en 
pleine terre et sans structure tombale, orientée N/S, était installée au centre de la nef, probablement quand l'église était réduite en état de ruines. Le défunt, une femme, portait seulement une bague en argent dont le chaton gravé d'un aigle stylisé. Les deux autres inhumations (T387 et T388), avaient été déposées dans des caissons de dalles, de typologie courante dans la nécropole principale, tous deux installés à l'ouest de l'entrée principale de l'église (fig. 32), qui par ailleurs n'a pas livré de narthex. D'autre sépultures en dalles ont été identifiées dans l'espace devant l'entrée et sur le côté sud de l'église, mais ce dossier funéraire qui se révèle très conséquent, est à reprendre dans les campagnes à venir.

Fig. 32 - Zone 1B. Église. Deux sépultures installées dans l'espace à l'ouest, devant l'église.

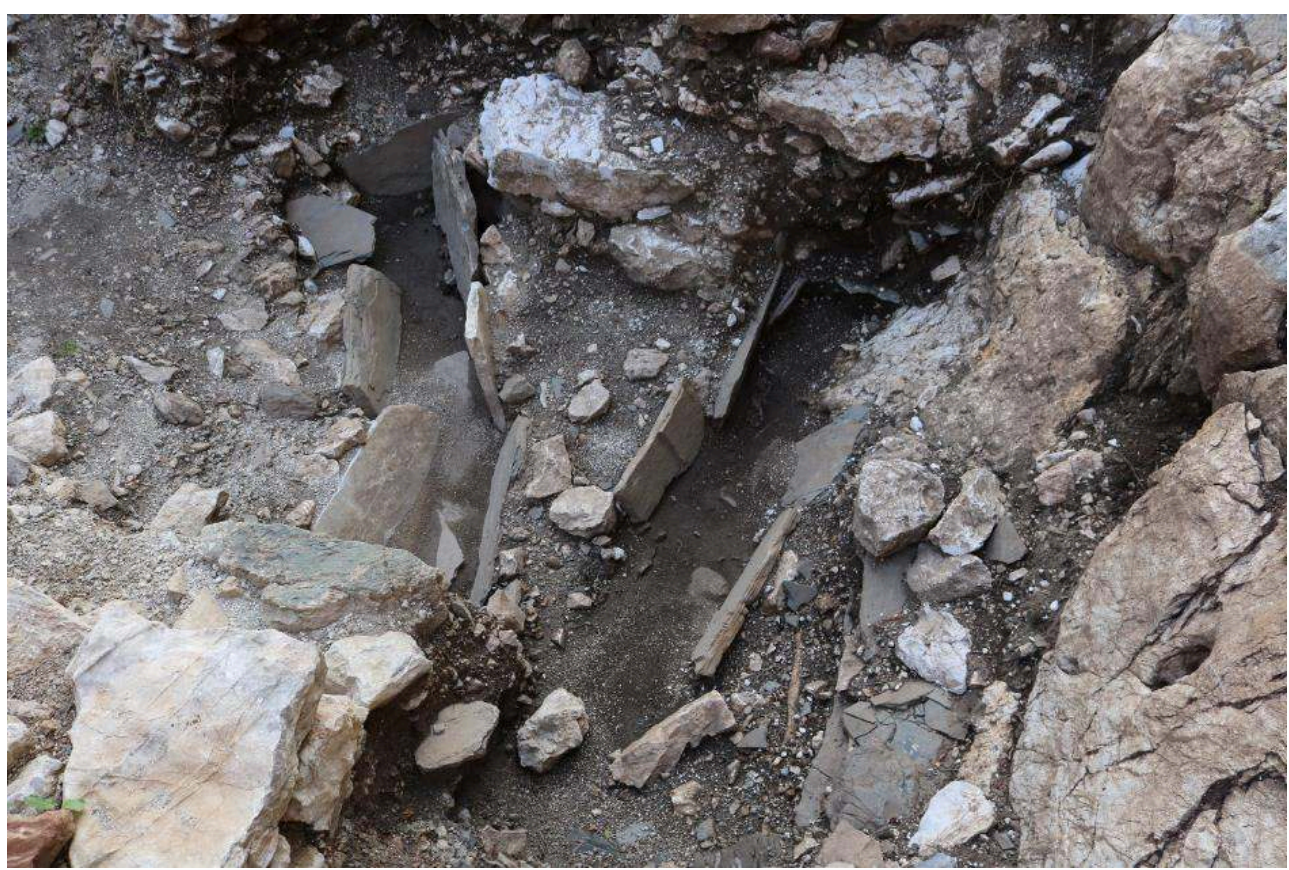

Cl. Y. Bonfand.

\section{La nécropole principale}

\section{État des connaissances}

À l'issue de la première mission de terrain 2017, qui a eu pour objectif d'évaluer le potentiel de la zone funéraire principale du site (zone 3 d'environ 4 ha), prospectée lors $\mathrm{du}$ quadriennal, et de poursuivre sa documentation suivant les opérations anciennes (années 1960 et 1982-1984), la localisation des aires funéraire a pu être établie et 13 premières tombes ont été mises au jour dans le secteur sondé et nommé « secteur A ».

\section{Les objectifs des campagnes 2018-2019 et les moyens à disposition}

29 L'équipe intervenant sur la nécropole a réuni dix personnes en 2018, et treize en 2019. Les résultats de la première mission 2017 ont permis de montrer le potentiel informatif et la nécessité de la documentation des tombes pour la compréhension de ce secteur majeur funéraire. Ainsi lors de ces deux missions de terrain, les objectifs étaient triples : 
- géolocaliser les structures ayant fait l'objet de fouilles anciennes (avant $1945 ; 1961$ et 1980-1984) afin d'avoir une vision de la répartition spatiale de l'aire funéraire principale du gisement, dans le but final de l'intégration des résultats des anciennes fouilles (demeurant non publiées) dans l'analyse globale des aires funéraires du site ; - poursuivre la documentation des structures funéraires du secteur A afin de comprendre l'organisation spatiale et le fonctionnement de cette partie de la nécropole qui se révèle très dense ;

- intervenir sur les structures dispersées dans d'autres aires funéraires qui nécessiteraient une documentation en vue de leur préservation, en particulier celles en relation avec l'église de la zone 1B, identifiées en 2017.

Secteur A, nécropole principale. Géolocalisation des aires de la nécropole fouillées anciennement

Dans ce but, nous avons commencé par identifier dans la documentation ancienne et les publications associées les plans de répartition de ces interventions (interventions pré-1945; 1961 et 1980-1984) (fig. 33).

Fig. 33 - Nécropole principale, zone 3. Relevé topographique des tombes fouillées dans les années 1980.

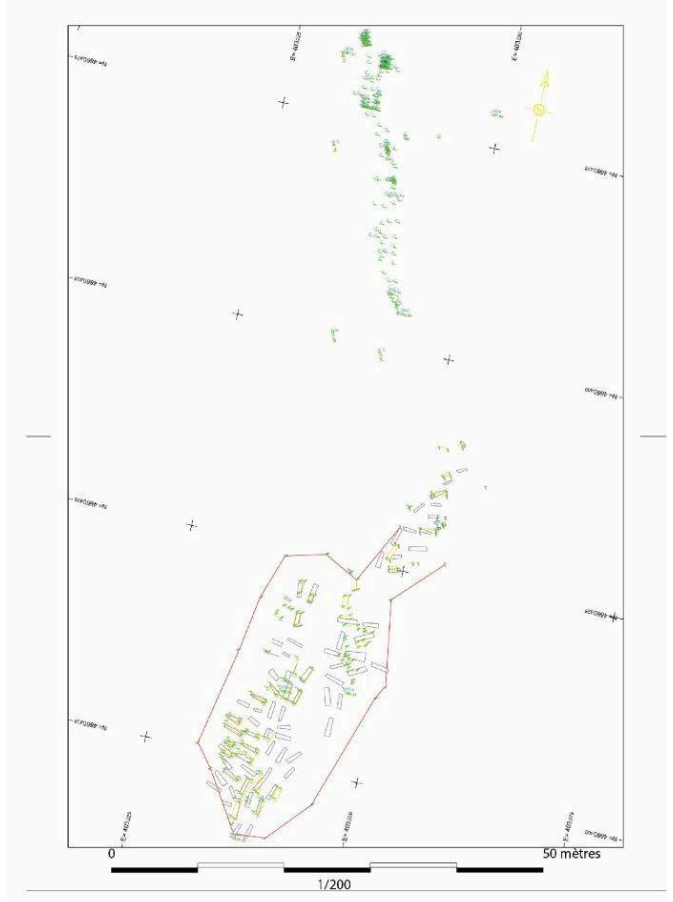

(c) Mission archéologique «Basse vallée du Drin », DAO : M. Ferrari, J. Desideri, E. Nallbani.

31 Nous avons eu à disposition les plans des 3 secteurs fouillés (nommés $\mathrm{A}$ à $\mathrm{C}$ ) dans les années 80 par l'archéologue Hëna Spahiu (archives de l'Institut d'Archéologie de Tirana). Ils ont été informatisés. Un emplacement à proximité du secteur A, nouvellement fouillé, était envisagé comme potentiel sous-secteur fouillé dans les années 1980. 
32 Après avoir nettoyé la végétation de la zone, nous avons cherché avec succès à recaler les différents plans sur les tombes identifiées à cet emplacement. Pour le secteur A du 1982, nous avons pu géolocaliser 32 tombes parmi les 69 identifiées sur le plan; pour le secteur $B$, seulement 3 tombes de géolocalisées parmi les 15 identifiées et pour le secteur C, des 10 tombes identifiées sur le plan, nous avons pu géolocaliser 6 d'entre elles.

\section{Documentation des tombes du secteur $\mathrm{A}$} documentation, par opération de fouilles, des structures funéraires du secteur A afin de
comprendre l'organisation spatiale et le fonctionnement de cette partie de la nécropole qui se révèle très dense.

Ainsi, 27 nouvelles sépultures ont été documentées et numérotées (fig. 34) en continu de celles de 2017, T. 403 à T. 429 (numérotation prenant en compte les tombes fouillées anciennement et les tombes ayant été documentées dans le secteur B1 de l'église).

Fig. 34 - Nécropole principale, zone 3. Relevée des tombes documentées, 2017-2019.

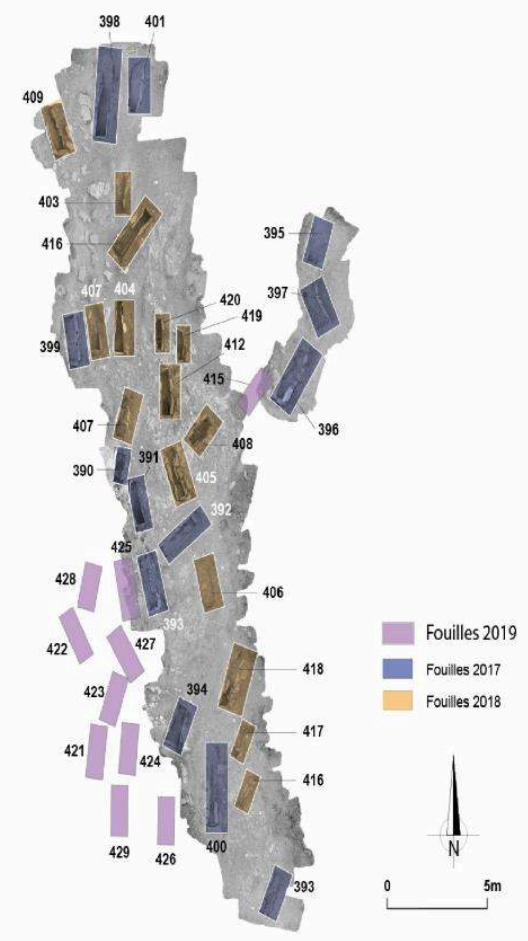

(c) Mission archéologique «Basse vallée du Drin », DAO : J. Desideri.

\section{8-2019, et d'un nouveau sous-secteur sous couvert végétal à l'extrême sud-est du} secteur A.

mi ces 27 nouvelles structures, nous avons eu l'opportunité de documenter trois tombes intactes, il s'agit des tombes T. 421, T. 423 et T. 424. Des 27 structures funéraires documentées dans le secteur $\mathrm{A}, 23$ sont orientée $\mathrm{S} / \mathrm{N}$ (dont 12 précisées et 11 non 
précisées) (fig. 35). Les sépultures semblent être toutes primaires. Elles sont - pour la plupart - plurielles.

Fig. 35 - Nécropole principale, zone 3. Caisson en ardoises, intacte, T424.
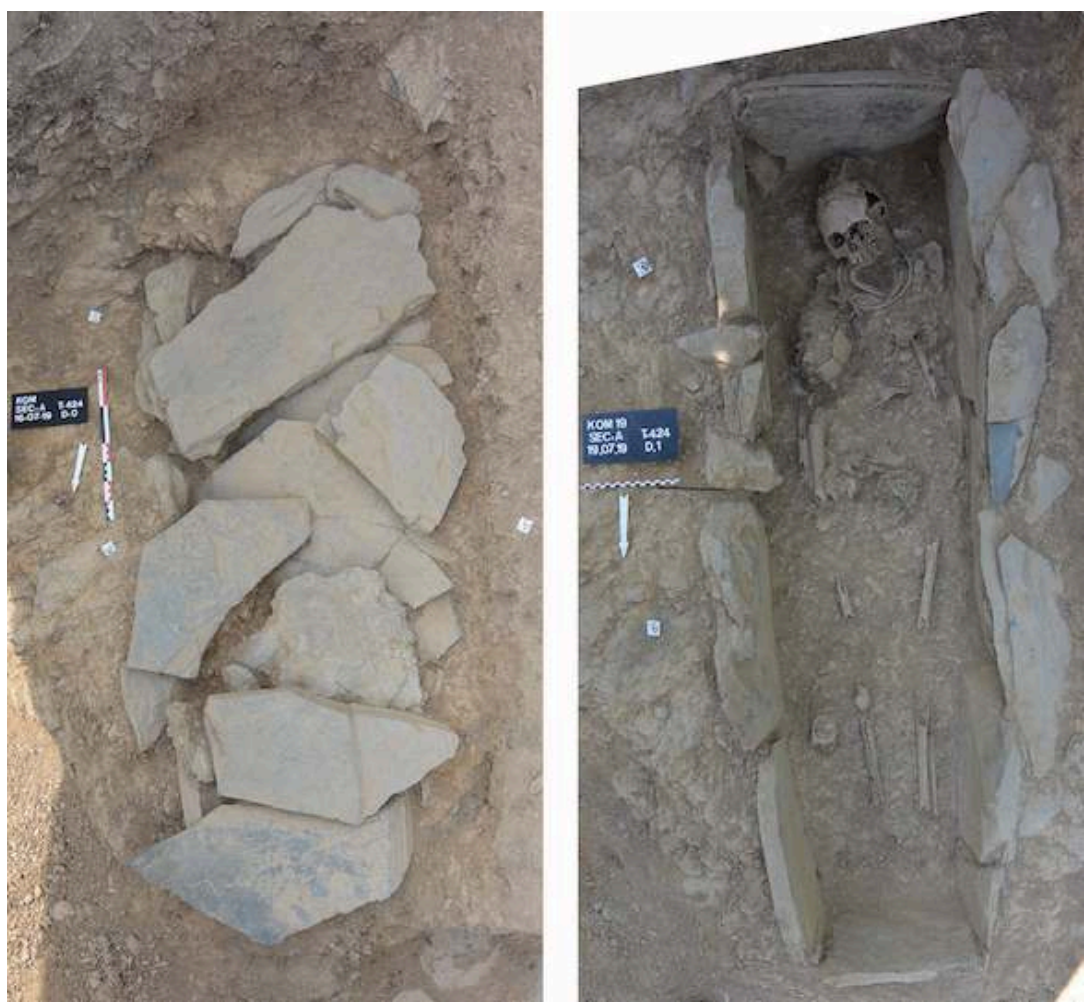

Cl. J. Desideri.

En ce qui concerne le recrutement funéraire, l'état de conservation extrêmement mauvais des ossements ne permet pas une attribution de l'identité biologique fiable pour la quasi-totalité des individus. La très large majorité des inhumés sont des adultes, à l'exception des tombes T. 419 (fig. 36) et T. 420 qui contiennent plusieurs immatures chacune et la T. 410 qui contient un adulte et un immature. Leur attribution sexuelle, se basant essentiellement sur des critères de robustesse et de gracilité, permet de proposer - mais avec grande prudence - que nous ayons peut-être une sépulture masculine (avec réduction masculine) pour T.422, une sépulture féminine (avec réduction féminine) pour T.424, une sépulture masculine (avec réduction indéterminée) pour T. 421 et une sépulture féminine pour T. 423. 
Fig. 36 - Nécropole principale, zone 3. Tombe 419 d'immatures.

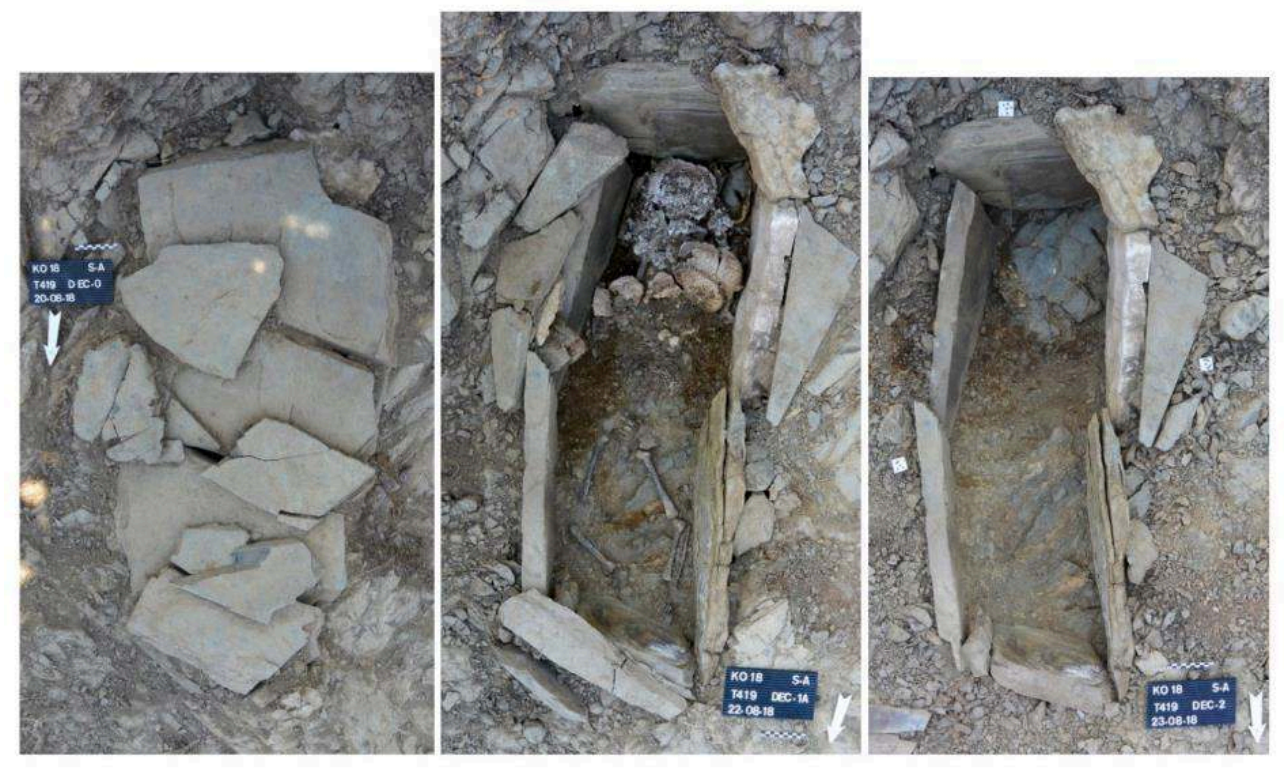

Cl. J. Desideri. préservation des ossements, à l'exception de 7 cas (T. 404, T. 405, T. 419, T. 421 à T. 424) où l'on constate que les individus ont été déposés en décubitus dorsal membres inférieurs allongés (voir fig. 36). Il est plus difficile de documenter la position des membres supérieurs souvent perturbés. Il a été possible d'identifier à deux reprises de vraies réductions localisées dans l'extrémité sud des structures. composé d'une dalle par largeur et de deux ou trois dalles par longueur. Les coffres sont de dimensions variables. Les longueurs varient entre 1,05 et 2,12 m, les largeurs entre 0,33 et $0,80 \mathrm{~m}$ et les profondeurs entre 0,17 et $0,55 \mathrm{~m}$. Les dimensions ne sont pas proportionnelles, ce qui confère parfois à certains coffres un aspect très étroit, notamment pour les grandes tombes. Le fond des structures n'est généralement pas aménagé et repose sur la roche-mère.

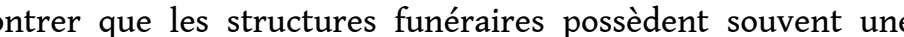
couverture formée de dalles en schiste ( $\mathrm{n}=14$, dont 6 complètes) (voir fig. 35-36). Parmi celles intactes, on constate que 3 d'entre elles présentent à l'emplacement du crâne (zone sud) une double (T.424 et T.426) ou triple (T.421) couche de dalles dont l'inférieure est - dans ces cas précis - en calcaire et non en schiste. Les tombes montrent des aménagements de dallettes en schiste probablement dans le but de stabiliser les dalles de couvertures. En revanche, il a été laborieux de documenter les fosses d'implantation des structures funéraires considérant la nature schisteuse du terrain encaissant. Ainsi, le niveau d'implantation, les limites, la taille, la forme et le fond des fosses ont été très difficile à identifier, à l'exception de la T. 412 pour laquelle la fosse était visible et des dallettes de calage étaient présentes.

majorité des inhumations (à l'exception de T. 407, T. 408, T. 413, T. 425, T. 427T. 429) a été accompagnée de mobilier, mais souvent perturbé. Il s'agit essentiellement d'éléments de costume (fibules, plaque-boucles et boucles de ceinture, fig. 37-38) de parures (torques, pendentifs, bracelets, anneaux, bagues, boucles d'oreilles...), mais 
aussi d'armes. A côté des nombreuses perles essentiellement en verre, le mobilier est composé quasi exclusivement d'éléments métalliques (torques, pendentifs, bracelets, anneaux, bagues, lames, fibules...).

Fig. 37 - Nécropole principale, zone 3. Plaque-boucle ajourée, tombe 423.
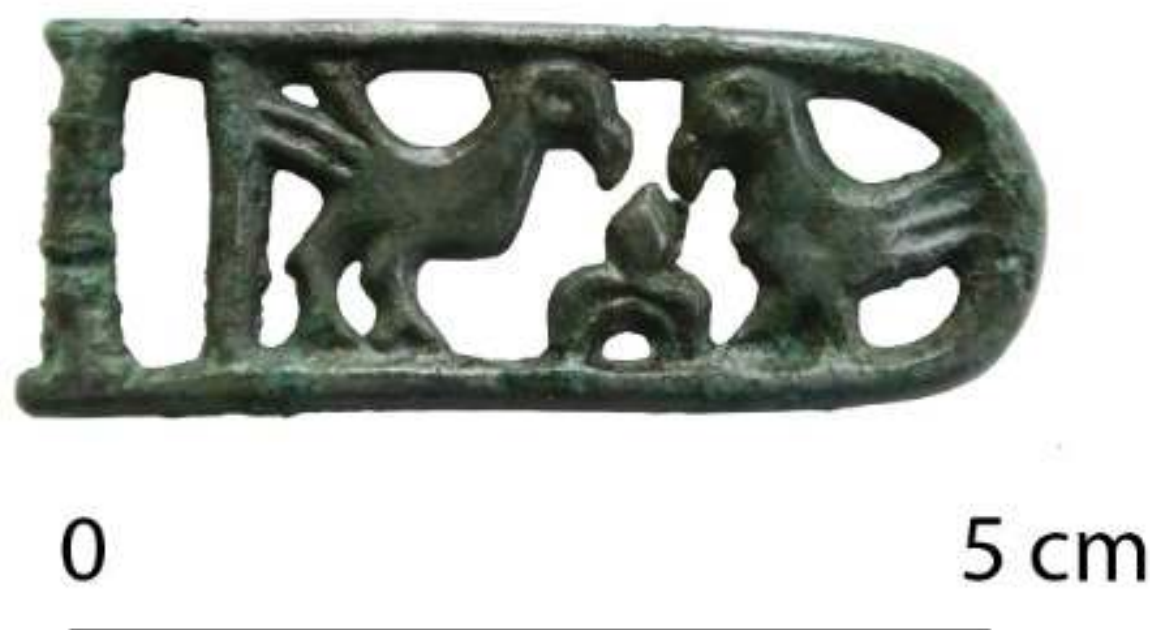

(c) Mission archéologique « Basse vallée du Drin », cl. E. Nallbani.

Fig. 38 - Nécropole principale, zone 3. Fibule au pied plié, tombe 424.

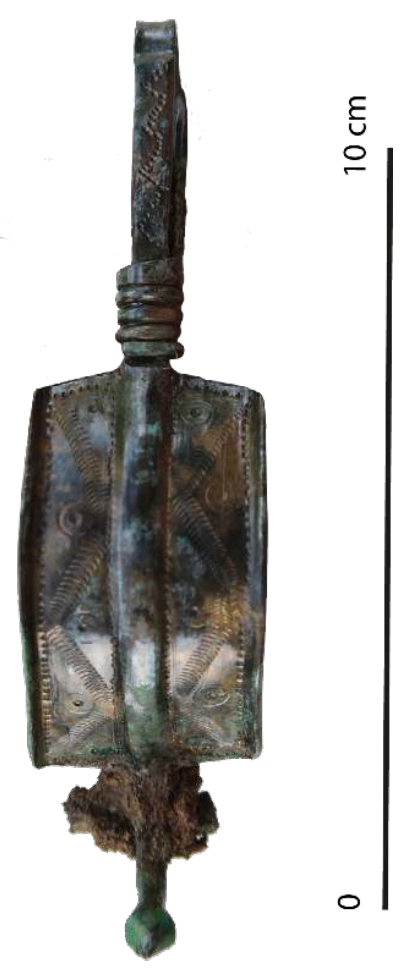

(c) Mission archéologique «Basse vallée du Drin », cl. E. Nallbani.

42 La documentation sur la nécropole principale de Komani permet non seulement de confirmer l'étendue relativement conséquente de l'espace funéraire, mais aussi l'importante densité des tombes. Une organisation de l'espace semble se dessiner avec 
des alignements de structures (fig. 39). La poursuite des investigations dans ce secteur (fig. 40) permettra de mieux appréhender la distribution et la structuration des sépultures au sein de la nécropole principale et, permettra, ainsi, une meilleure compréhension du fonctionnement de celle-ci.

Fig. 39 - Fouille dans la nécropole principale, zone 3. Sépultures en rangées.

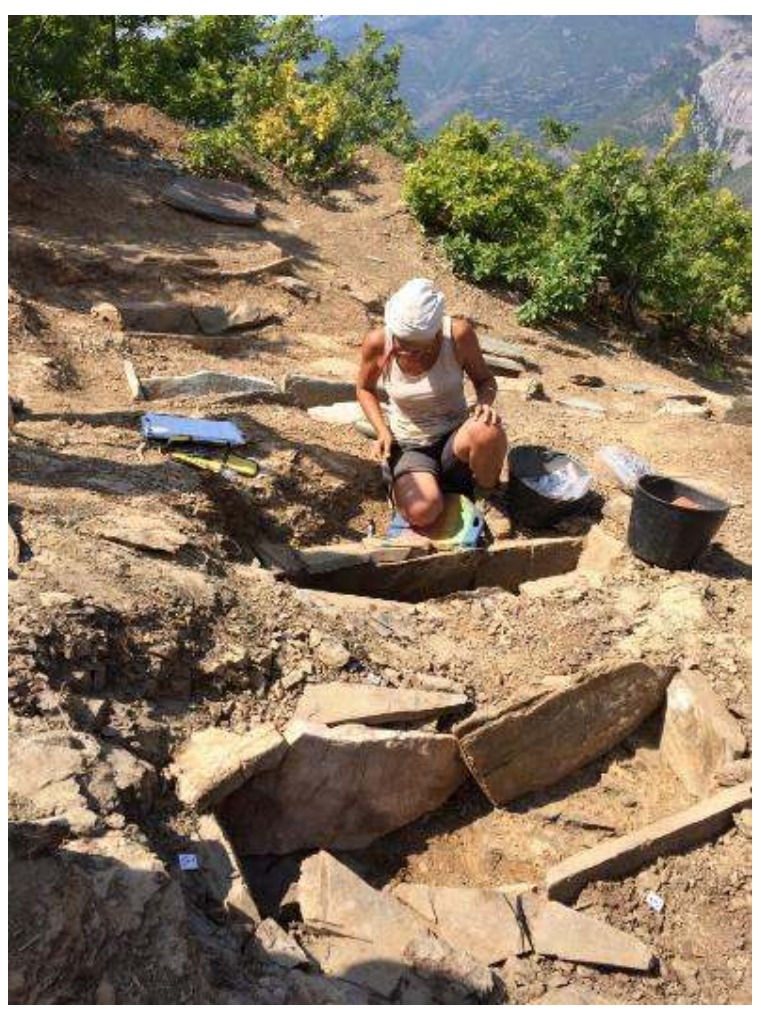

Cl. J. Desideri. 
Fig. 40 - Fouille dans la nécropole principale, zone 3.

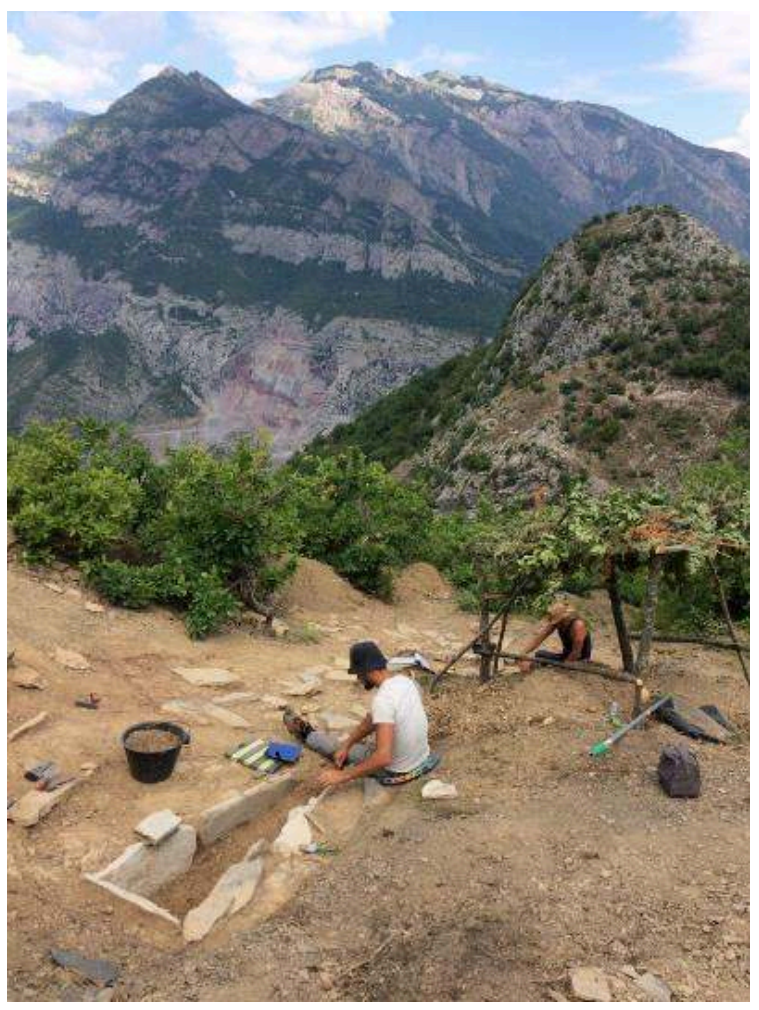

Cl. E. Nallbani.

\section{Travaux de restauration et de valorisation à Komani}

Les actions de mise en valeur du site et de restaurations se sont poursuivies en 2018 avec la restauration de tout le mobilier des sépultures par E. Bitri et ont été renforcées avec l'intégration des étudiants de ESCRBCG au programme de la restauration en 2019.

De travaux consistants de consolidations et restaurations ont été engagé dans l'église de la zone 1B, où D. Margjoni (restaurateur au DRTK de Shkodra), secondé par des étudiants espagnols et trois ouvriers, ont consolidé toute la partie sud de l'église (fig. 41) et des fragments d'enduis peint dans le cœur (fig. 42). Le mobilier issu de 10 tombes, fouillées en 2019 (nécropole principale et très peu de l'église) a été entièrement restauré par l'équipe de l'école de restauration l'ESCRBCG. Outre la totalité des objets (bronze, fer, argent et verre) découverts en 2019, l'équipe a également restauré une dizaine d'objets mis au jour des anciennes fouilles (1982-1984), mais qui n'ont jamais été traités auparavant. Ils présentaient un intérêt particulier pour l'étude globale du matériel de la nécropole de Komani, y compris les résultats des anciennes fouilles de la nécropole. L'équipe a également traité les enduits peints, y compris le panneau à inscription, les blocs d'architecture et les décors en stuc. 
Fig. 41 - Zone 1B. Mur sud de l'église, après restauration.

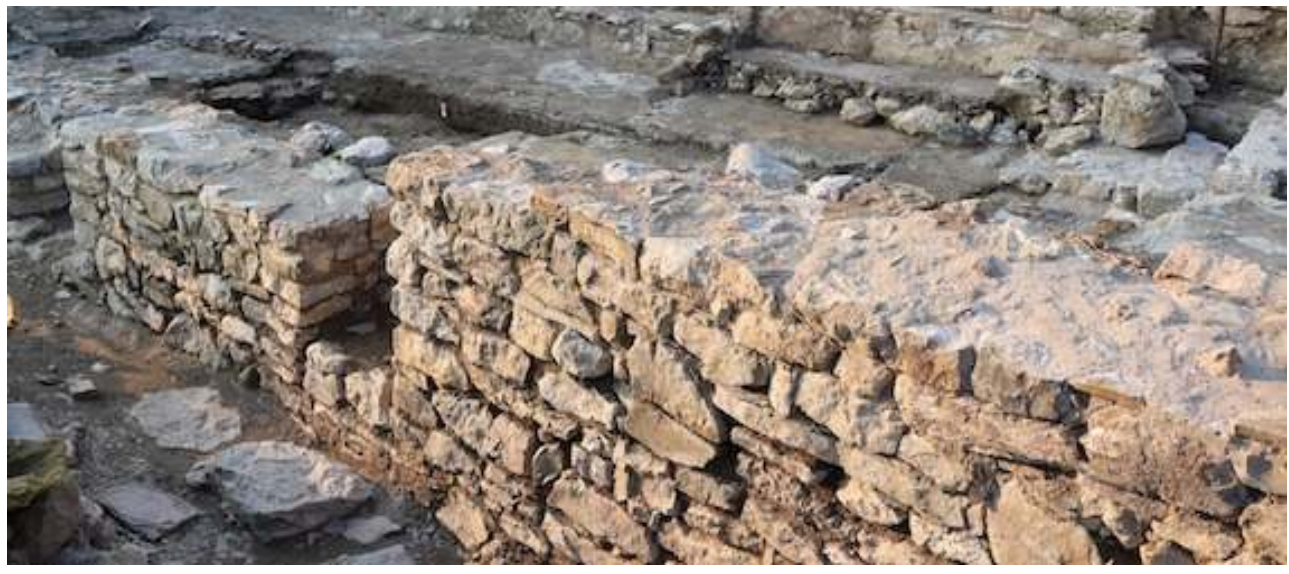

Cl. Y. Bonfand.

Fig. 42 - Zone 1B. Consolidation des enduits peints dans l'église.

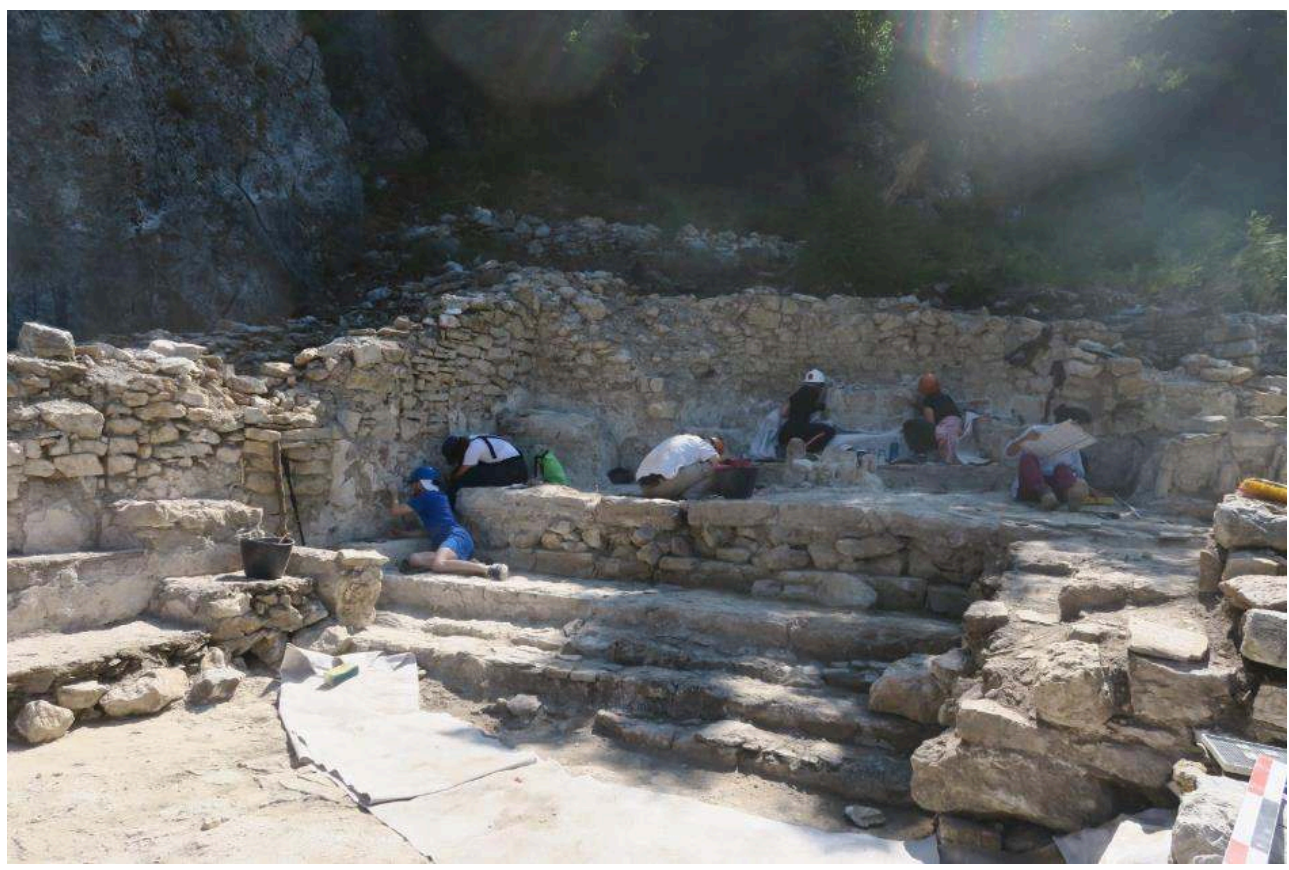

Cl. E. Nallbani.

L'action de la gestion patrimoniale du site de Komani dans le cadre de la Vallée du Drin, a poursuivi par la formation de R. Gradeci au stage du Pôle international francophone de formation et d'échanges de gestionnaires des sites patrimoniaux, organisé par le RGSF, à Bibracte en avril 2019; la création du Parc Naturel Municipal de la Vallée du Drin «Lugina e Drinit Bashkia Vau Dejës » en juin 2019 et l'organisation en cours, d'un atelier de formation sur la gestion des sites patrimoniaux dans les Balkans, centré sur le site de Komani dans la « Vallée du Drin », qui aura lieu en mai 2020 (fig. 43). 
Fig. 43 - L'équipe partielle de la mission de terrain 2019.

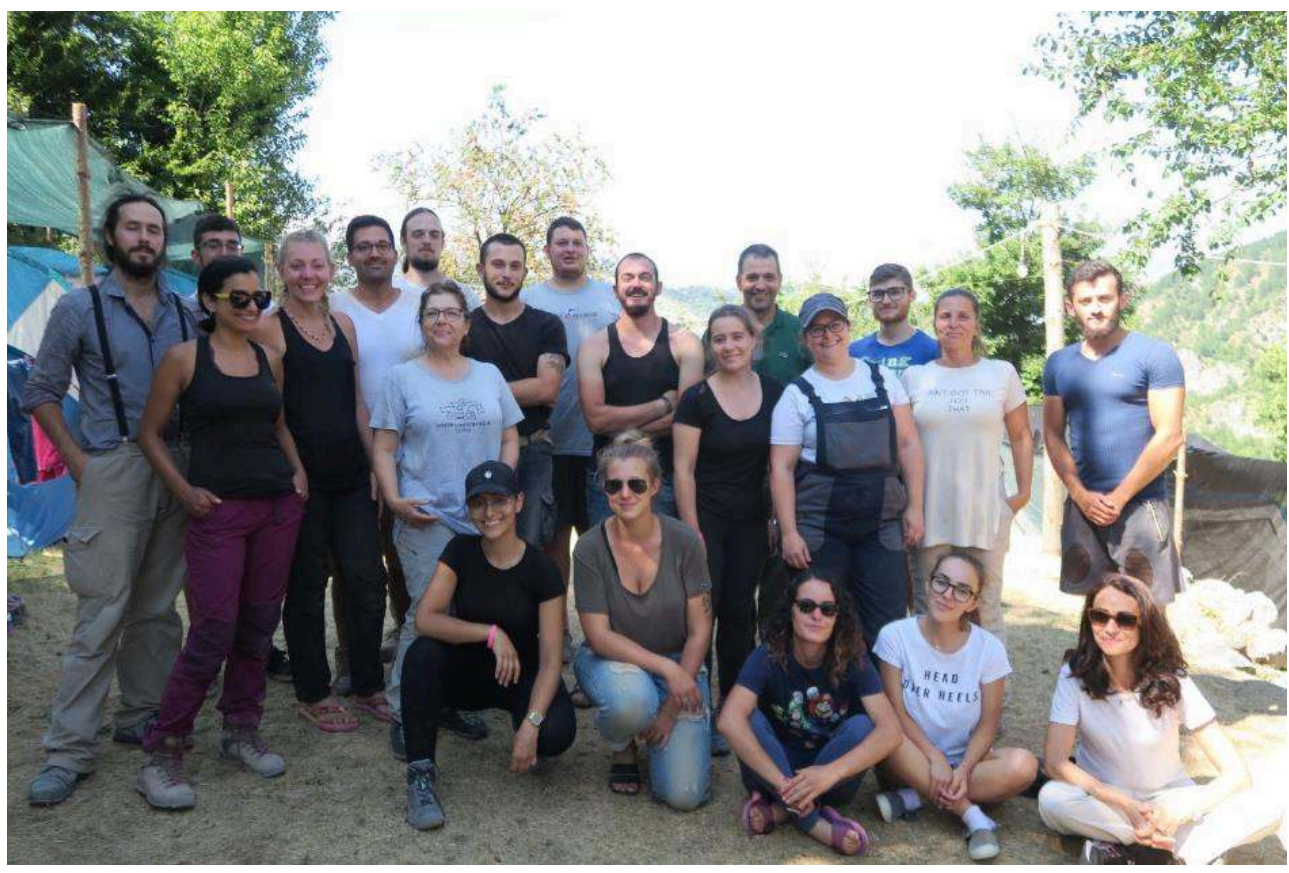

Cl. R. Nikaj.

\section{NOTES}

1. https://journals.openedition.org/cefr/2491, fig. 12-16.

2. https://journals.openedition.org/cefr/2491, fig. 24.

3. https://journals.openedition.org/cefr/2357, fig. 44.

\section{INDEX}

Index géographique : Albanie, Komani

institutions EFR, Institut d'Archéologie de Tirana, Ministère de l'Europe et des Affaires Etrangères, Labex RESMED, université de Genève, UMR Orient et Méditerranée 8167 et CEPAM 7264 du CNRS

Mots-clés : Albanie, vallée du Drin, Komani, Sarda, Moyen Âge, archéologie, télédétection Lidar, nécropole, tombe, mobilier funéraire, église, aménagements liturgiques, synthronon, enduit peint 


\section{AUTEURS}

\section{ETLEVA NALLBANI}

CNRS, UMR 8167/Orient et Méditerranée, Paris - etleva.nallbani@college-de-france.fr

\section{YANN BONFAND}

Université Grenoble-Alpes (LUHCIE), chercheur associé à l'ARAR (UMR 5138) -

yann.bonfand@laposte.net

\section{JOCELYNE DESIDERI}

Université de Genève, Laboratoire d'archéologie préhistorique et anthropologie/LAP jocelyne.desideri@unige.ch

\section{ELVANA METALLA}

Institut d'Archéologie de Tirana - emetalla@hotmail.com 